Delft University of Technology

\title{
Impacts of Tropical Cyclones on the Caribbean Under Future Climate Conditions
}

Kleptsova, Olga S.; Dijkstra, Henk A.; van Westen, René M.; van der Boog, Carine G.; Katsman, Caroline A.; James, Rebecca K.; Bouma, Tjeerd J.; Klees, Roland; Riva, Riccardo E.M.; Slobbe, D. Cornelis

DOI

10.1029/2020JC016869

Publication date

2021

Document Version

Final published version

Published in

Journal of Geophysical Research: Oceans

\section{Citation (APA)}

Kleptsova, O. S., Dijkstra, H. A., van Westen, R. M., van der Boog, C. G., Katsman, C. A., James, R. K., Bouma, T. J., Klees, R., Riva, R. E. M., Slobbe, D. C., Zijlema, M., \& Pietrzak, J. D. (2021). Impacts of Tropical Cyclones on the Caribbean Under Future Climate Conditions. Journal of Geophysical Research: Oceans, 126(9), [e2020JC016869]. https://doi.org/10.1029/2020JC016869

Important note

To cite this publication, please use the final published version (if applicable).

Please check the document version above.

\section{Copyright}

Other than for strictly personal use, it is not permitted to download, forward or distribute the text or part of it, without the consent of the author(s) and/or copyright holder(s), unless the work is under an open content license such as Creative Commons.

\section{Takedown policy}

Please contact us and provide details if you believe this document breaches copyrights.

We will remove access to the work immediately and investigate your claim. 


\section{JGR Oceans}

\section{RESEARCH ARTICLE}

10.1029/2020JC016869

Key Points:

- Only minor changes in the hurricane-induced extreme water levels in the Northeast Caribbean are expected under future climate conditions

- Global sea-level rise remains the main coastal flood risk factor provided that hurricane intensity is unchanged

- Southern Caribbean can become more vulnerable to coastal erosion and flooding by increased wave setup

Correspondence to:

O. S. Kleptsova,

okleptsova@gmail.com

Citation:

Kleptsova, O. S., Dijkstra, H. A., van Westen, R. M., van der Boog, C. G., Katsman, C. A., James, R. K., et al. (2021). Impacts of tropical cyclones on the Caribbean under future climate conditions. Journal of Geophysical Research: Oceans, 126, e2020JC016869. https://doi.org/10.1029/2020JC016869

Received 12 OCT 2020 Accepted 18 AUG 2021

\section{Impacts of Tropical Cyclones on the Caribbean Under Future Climate Conditions}

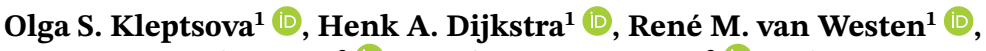 \\ Carine G. van der Boog ${ }^{2}$ (D) Caroline A. Katsman ${ }^{2}$ (), Rebecca K. James ${ }^{3}$ (D), \\ Tjeerd J. Bouma ${ }^{3}$, Roland Klees ${ }^{4}$ (D), Riccardo E. M. Riva ${ }^{4}$ (D) D. Cornelis Slobbe ${ }^{4}$ (1), \\ Marcel Zijlema ${ }^{2}$, and Julie D. Pietrzak ${ }^{2}$ (1)
}

${ }^{1}$ Institute for Marine and Atmospheric Research, Utrecht University, Utrecht, The Netherlands, ${ }^{2}$ Department of Hydraulic Engineering, Environmental Fluid Mechanics, Faculty of Civil Engineering and Geosciences, Delft University of Technology, Delft, The Netherlands, ${ }^{3}$ Estuarine and Delta Systems, Royal Netherlands Institute for Sea Research and Utrecht University, Yerseke, The Netherlands, ${ }^{4}$ Department of Geoscience and Remote Sensing, Faculty of Civil Engineering and Geosciences, Delft University of Technology, Delft, The Netherlands

\begin{abstract}
Joint effects of the dynamic sea-level rise projected changes in the large-scale atmosphere/ ocean circulation, and wave climate on hurricane-induced extreme water levels in the Caribbean region are assessed. We use the 2D-depth integrated ADCIRC + SWAN wave-ocean model, baroclinically coupled to an ocean-eddying version of the Community Earth System Model, to compare impacts of the September 2017 hurricanes with projected impacts of similar hypothetical tropical storms occurring in the future. The model predicts only minor changes in the hurricane-induced extreme water levels for those Caribbean islands which were severely devastated by the 2017 tropical storms (Irma and Maria). That is, provided that the hurricane intensity remains at the present-day level, the global mean sea-level rise is the main future coastal flood risk factor.
\end{abstract}

Plain Language Summary The unique geophysical setting makes the Caribbean region extremely vulnerable to climatic changes experienced over the past few decades. The majority of the population and important infrastructures such as ports and airports are concentrated in the coastal zones which are at risk of permanent flooding as sea level continues to rise. The economy of the small Caribbean islands is heavily dependent on tourism and associated industries which are under pressure due to coral bleaching and coastal erosion. Additionally, the Caribbean region experiences intense and frequent extreme weather events which can potentially become more destructive in the future. As it is uncertain whether the hurricanes themselves will change, we investigate how the present-day tropical cyclones will impact the Caribbean in the future. Our results indicate that islands in the Northeast Caribbean will not be at higher risk of hurricane-induced flooding in the future if coastal infrastructure and ecosystems (coral reefs and seagrass meadows) can withstand the sea-level rise and continue to provide important coastal protection services. In contrast, the projected increase in wave height in the southern Caribbean can lead to more coastal flooding and beach erosion in these areas.

\section{Introduction}

Sea-level rise poses severe threats to low-lying coastal areas globally, and the Caribbean region is recognized as being one of the most vulnerable regions of the world (Mycoo, 2018; Nurse et al., 2014). The vulnerability arises from geophysical characteristics of small islands and coastal topographic settings, which limit where population and economic centers can be located. While the land area permanently inundated by $1 \mathrm{~m}$ sea-level rise will not exceed 5\% for any of the Caribbean Community states, the most valuable land for tourism, agriculture, and transportation infrastructure will be lost. The effects of sea-level rise on the economy of the Caribbean region can therefore be dramatic (Simpson et al., 2010).

In addition, tropical storms and hurricanes developing over warm Atlantic waters present major hazards for coastal areas in the Caribbean due to the associated extreme winds, rainfall, and storm surges. The Atlantic tropical cyclone activity has shown clear increasing trends in the observed genesis number, the number of intense hurricanes and mean maximum intensity over the past decades (Kossin et al., 2013; Landsea et al., 2010; Murakami et al., 2014). However, the tropical cyclone activity levels in the Atlantic basin are 
subject to significant multidecadal variability attributed to natural changes in the meridional overturning ocean circulation (Delworth \& Mann, 2000; Klotzbach \& Gray, 2008), volcanic eruptions, and Sahara dust outbreaks (Evan et al., 2011; Evan, 2012), as well as to changes in the anthropogenic forcing factors such as greenhouse gases and sulphate aerosols (Evan et al., 2009). The relative contribution of each mechanism to the observed tropical cyclone variability is presently an active area of research. Projections on whether tropical storm frequency and intensity in the Atlantic basin will increase during the 21st century under greenhouse gas forcing vary considerably between the studies (T. R. Knutson et al., 2013; T. Knutson et al., 2019; Villarini \& Vecchi, 2012; Villarini \& Vecchi, 2013; Walsh et al., 2016). Additionally, Colbert et al. (2013) estimated fewer westward tracks and more recurving (open-ocean) tracks in the North Atlantic at the end of the twenty-first century. These changes in the cyclone tracks would imply a decrease in landfall in the Caribbean region and North America, independent of overall changes in the activity.

While it is uncertain if tropical cyclones will change in the future, it is important to assess whether the impacts of the present-day hurricanes will alter under climate change. As the climate warms, the global mean sea level is projected to rise, due to thermal expansion and melting of land ice (IPCC, 2019), thereby increasing the risk of storm-induced flooding in the low-lying areas (Kleinosky et al., 2007; Mousavi et al., 2011; Smith et al., 2010). Regional sea-level changes may, however, deviate from the global sea-level trend due to, among others, local land subsidence, changes in the ocean circulation, and mesoscale eddy activity (Hu et al., 2011; Torres \& Tsimplis, 2013; van Westen et al., 2020). Melet et al. (2018) found that the contribution of wave setup to coastal water levels can exceed the contribution from thermal expansion. Wolf and Woolf (2006) and Joyce et al. (2019) have shown that changes in synoptic wind fields do not only influence wave climate (and hence coastal wave setup) but also hurricane-induced wave heights. Besides that, sea-level rise, alterations to coastal morphology and ice sheet extent, changes in ocean baroclinicity can alter the tidal amplitude and phases (Haigh et al., 2020). This, in turn, would change the water level during hurricane passage and, thus, influence the surge. Non-linear interactions between water depth, tide, waves, and atmospheric surge could, thus, lead to changes in the peak water levels which are significantly different from the changes in the mean sea level alone (Arns et al., 2015; Idier et al., 2019). Assessing the impact of climate change on hurricane-induced flooding, therefore, requires explicit storm surge modeling under future climate conditions. Since tropical storms and surges cannot be modeled directly in the low-resolution general circulation models used in climate studies, downscaling to high-resolution regional models is required.

Storm surge forecasting is usually done using 2D-barotropic models, which do not take into account density or vertical velocity structure. Such models are unable to represent the important baroclinic ocean processes described above. Although it is possible to conduct surge forecasting with 3D models, these are still too expensive, so either temporal or spatial resolution needs to be sacrificed. Pringle et al. (2019) developed a depth-integrated model, which accounts for the effects of the oceanographic processes on the free surface and depth-integrated currents. This was achieved by means of one-way coupling ADvanced CIRCulation + Simulating WAves Near Shore (ADCIRC + SWAN; Dietrich et al. [2011]) model to the operational data-assimilated Global Ocean Forecasting System (GOFS 3.1, see Metzger et al. [2017]). Pringle et al. (2019) showed that the 2D baroclinically-coupled ADCIRC is capable of reproducing the effects of the seasonal water-level cycle, the large-scale ocean dynamics, as well as the impacts of the sea-level change due to trailing cold wakes in the ocean surface temperature caused by vertical mixing from the passing hurricanes. The inclusion of ocean baroclinicity with parameterized internal tide conversion also improved the representation of the tidal dynamics.

Following the approach of Pringle et al. (2019), we develop the baroclinic coupling of ADCIRC + SWAN (Dietrich et al., 2011) to the Community Earth System Model (CESM, Padua [2011]). The coupled model is used to assess how the ongoing sea-level rise and the projected changes in the large-scale ocean/atmosphere circulation will influence the storm inundation risk for the Caribbean islands. We compare impacts of the 2017 Irma and Maria tropical storms to that of September-specific warming scenarios for 2080-2100. The model used will be described in Section 2 and the numerical implementation and future scenario in Section 3. The comparison between tide-gauge observations and the results of the present-day model configuration is described in Section 4. The impact of tropical cyclones on the Caribbean region under climate change is presented in Section 5, followed by a summary and discussion in Section 6. 


\section{Model Description}

Simulations are performed using the finite element ADCIRC + SWAN model (Dietrich et al., 2011) in a baroclinic-coupled depth-integrated configuration (see Pringle et al. [2019]). In this configuration the baroclinic processes are not simulated directly, but their effects on the free surface and depth-integrated currents are accounted for. The coupling procedure is similar to the explicit external-internal mode-splitting schemes used in the ocean models (Shchepetkin \& McWilliams, 2005), but modes are only weakly one-way coupled here. The baroclinic-coupled depth integrated model (which we will refer to below as 2DBC) uses information from an external 3D-baroclinic model to compute depth-integrated baroclinic pressure gradients $(\nabla B)$, the depth integrated momentum dispersion $(\nabla D)$ and the dissipation vector $(C)$ due to the energy conversion from barotropic tides to baroclinic internal tides. These terms enter the standard shallow water equations in the form of additional sinks as follows

$$
\begin{gathered}
\frac{\partial \zeta}{\partial t}+\nabla \cdot(\boldsymbol{U} H)=-\sigma(\boldsymbol{x})\left(\zeta-\zeta_{c}\right) \\
\frac{\partial \boldsymbol{U}}{\partial t}+\boldsymbol{U} \cdot \nabla \boldsymbol{U}+f \mathbf{k} \times \boldsymbol{U}=-\nabla\left[\frac{p_{s}}{\rho_{0}}+g\left(\zeta-\zeta_{E Q}-\zeta_{S A L}\right)\right] \\
+\alpha\left[\frac{\nabla M}{H}-\frac{\nabla D}{H}-\frac{\nabla B}{H}-C\right]+\frac{\tau_{s}-\tau_{b}}{\rho_{0} H}-\sigma(\boldsymbol{x})\left(\boldsymbol{U}-\boldsymbol{U}_{c}\right),
\end{gathered}
$$

where $\zeta$ is the free surface elevation. The total water depth is defined as $H=b+\zeta$, where $b$ is the still water depth. $\boldsymbol{U}$ denotes the depth-averaged velocity vector, $g$ is the acceleration due to gravity and $f$ is the Coriolis parameter. The atmospheric pressure at the free surface is denoted as $p_{s}$ and $\rho_{0}=1000 \mathrm{~kg} / \mathrm{m}^{3}$ is the reference density of water. The quantities $\zeta_{E Q}$ and $\zeta_{S A L}$ are the equilibrium tide and the ocean self-attraction and loading term, respectively. The horizontal momentum diffusion $\nabla M$ is approximated through the Smagorinsky closure model (Smagorinsky, 1963). Finally, the stresses at the sea surface and bed are denoted as $\tau_{s}$ and $\tau_{b}$, respectively. If the coefficient $\alpha=1$, the $2 \mathrm{D}$ baroclinic coupling is invoked; setting $\alpha=0$ reverts the model to the 2D barotropic model (which we will refer to below as BT).

The depth-integrated baroclinic pressure gradient is calculated as

$$
\nabla B=\int_{-b}^{\zeta} g \nabla\left[\int_{z}^{\zeta} \frac{\rho-\rho_{0}}{\rho_{0}} d z^{\prime}\right] d z
$$

where $\rho$ is the density field from the external 3D-baroclinic model (in our case, CESM). The upper limit on the integral $\zeta$ is obtained from the ADCIRC model during the simulation at each time step.

The depth-resolving $(\boldsymbol{v})$ and depth-averaged $(\boldsymbol{V})$ baroclinic velocity fields are used to calculate the depth-integrated momentum dispersion:

$$
\nabla D=\nabla \int_{-b}^{0}[(\boldsymbol{v}-\boldsymbol{V}) \cdot(\boldsymbol{v}-\boldsymbol{V})] d z
$$

The dissipation vector $C$ due to the energy conversion from barotropic tides to baroclinic internal tides is calculated using the local generation formulation described in Pringle, Wirasaet, and Westerink (2018):

$$
C=\frac{\sqrt{\left(N_{b}^{2}-\omega^{2}\right)\left(\bar{N}^{2}-\omega^{2}\right)}}{\pi \omega}\left(\nabla b \cdot \boldsymbol{U}_{\boldsymbol{T}}\right) \nabla b
$$

Here $\boldsymbol{U}_{T}$ is the prescribed depth-averaged tidal velocity vector, $\omega$ is set to the angular frequency of the $M_{2}$ tidal constituent, $N_{b}$ and $\bar{N}$ are the sea bed and the depth-averaged buoyancy frequency respectively. To prevent excessive dissipation on the continental shelves, $C$ is set to zero for the areas where the still water depth $b$ is less than 100 meters.

To avoid artificial reflections that contaminate the solution, a sponge layer that absorbs outgoing oceanic information is defined near the lateral open boundary. $\sigma(\boldsymbol{x})$ indicate the spatially varying coefficients in the absorption-generation sponge layer region, see Pringle, Wirasaet, Suhardjo, et al. (2018). $\zeta_{c}$ and $\boldsymbol{U}_{c}$ are the free surface and velocity tidal reference solutions that are applied in the sponge layer. 


\section{Numerical Setup, Experiment Design, Observations}

\subsection{Numerical Setup: September 2017}

We employ a high-resolution unstructured grid of Puerto Rico, the Virgin Islands, and the Caribbean Sea (PRVI15) created by Joyce et al. (2019) for the ADCIRC Surge Guidance System (ASGS, https://cera.coastalrisk.live). The grid resolution varies from approximately $10 \mathrm{~km}$ in the deep regions of the North Atlantic Ocean and Gulf of Mexico to 30-100 m along the coastlines of Puerto Rico and the US Virgin Islands (Figure 1a).

Ocean baroclinicity and atmospheric data are drawn from climate model simulations performed with version 1.0.4 of the CESM (van Westen et al., 2020). This high-resolution configuration of CESM has a nominal horizontal resolution of $1 / 10^{\circ}$ for the ocean component and $1 / 2^{\circ}$ for the atmosphere component. The simulation used is branched off from a 200-years control simulation (under year 2000 forcing) and was forced with a $1 \%$ increase of $\mathrm{CO}_{2}$ over the period 2000-2100. This forcing is retained from the Representative Concentration Pathway (RCP) 8.5 scenario (Stocker et al., 2013).

The 10-m winds $\left(\boldsymbol{u}_{10}\right)$ required by ADCIRC are approximated from the CESM winds $\left(\boldsymbol{u}_{0}\right)$ at lowermost model level $\left(H_{0} \approx 60 \mathrm{~m}\right)$ using a logarithmic law

$$
\boldsymbol{u}_{10}=\frac{\log \left(10 / z_{0}\right)}{\log \left(H_{0} / z_{0}\right)} \boldsymbol{u}_{0}
$$

with an open ocean roughness coefficient $z_{0}=0.0002 \mathrm{~m}$.

Since tropical cyclones are not simulated by CESM, the cyclone data were extracted from ERA5 (Copernicus Climate Change Service (C3S), 2017). ERA5 is the latest ECMWF atmospheric reanalysis of the global climate produced at a 1-hourly time step and has a horizontal resolution is $0.25^{\circ}$. The daily CESM atmospheric data are upsampled to ERA5 spatial and temporal resolution. ERA5 mean sea-level pressure and 10-m wind velocity fields were smoothed using a 14-days moving average. Differences between the original ERA5 and the filtered fields represent the diurnal and short-term weather-related variations. These were superimposed onto the upsampled CESM mean sea-level pressure and 10-m wind velocity fields.

The density field needed for the calculation of the baroclinic forcing terms given by Equations 3-5 was reconstructed from the CESM temperature and salinity fields using the GSW Oceanographic Toolbox (McDougall \& Barker, 2011). The baroclinic pressure gradients and buoyancy frequency terms were first calculated on a structured grid with uniform $1 / 10^{\circ}$ horizontal resolution and 42 vertical levels. For the calculation of the horizontal gradients, a second-order central finite-difference scheme was employed. Depth-integration is performed using the trapezoidal rule. The daily $\nabla B, \nabla D$ and $C$ values were then bi-linearly interpolated in space onto the ADCIRC unstructured computational grid and linearly interpolated in time at each computational step.

To account for the effects of the oceanic processes that develop outside of the computational domain, the SSH drawn from the CESM is specified at the lateral open boundary. This elevation is added to the tidal reference solutions reconstructed using TPXO9.1 (Egbert \& Erofeeva, 2002) eight major harmonic tidal constituents M2, S2, N2, K2, K1, O1, Q1, and P1. To account for the long-term tidal variability, nodal/satellite corrections were applied.

In the interior domain, tidal potential forcing was applied using the same constituents as are forced on the open ocean boundary. Additionally, ocean self-attraction and loading term was interpolated from FES2014, produced by Noveltis, Legos, and CLS and distributed by AVISO+, with support from CNES (https://www. aviso.altimetry.fr/). At the sea bed a quadratic stress parameterization with the bottom drag coefficient dependent on the Manning's $n_{M}$ coefficient and depth at each mesh node (Kerr et al., 2013) was applied for $\tau_{b}$. For the Atlantic Ocean the value of $n_{M}$ was set to 0.025 , while in the Caribbean Sea, $n_{M}=0.028$ was used. Frictional effects of coral reefs and mangroves covering an extensive area near Caribbean islands (Giri et al., 2011; Kendall et al., 2001) were accounted for by using $n_{M}=0.220$ (Kennedy et al., 2012) and $n_{M}=0.400$ (Wolanski et al., 1992), respectively. The free surface stress $\tau_{s}$ due to winds was computed according to Garratt's drag law (Garratt, 1977) with the drag coefficient set to an upper limit of 0.0035. 

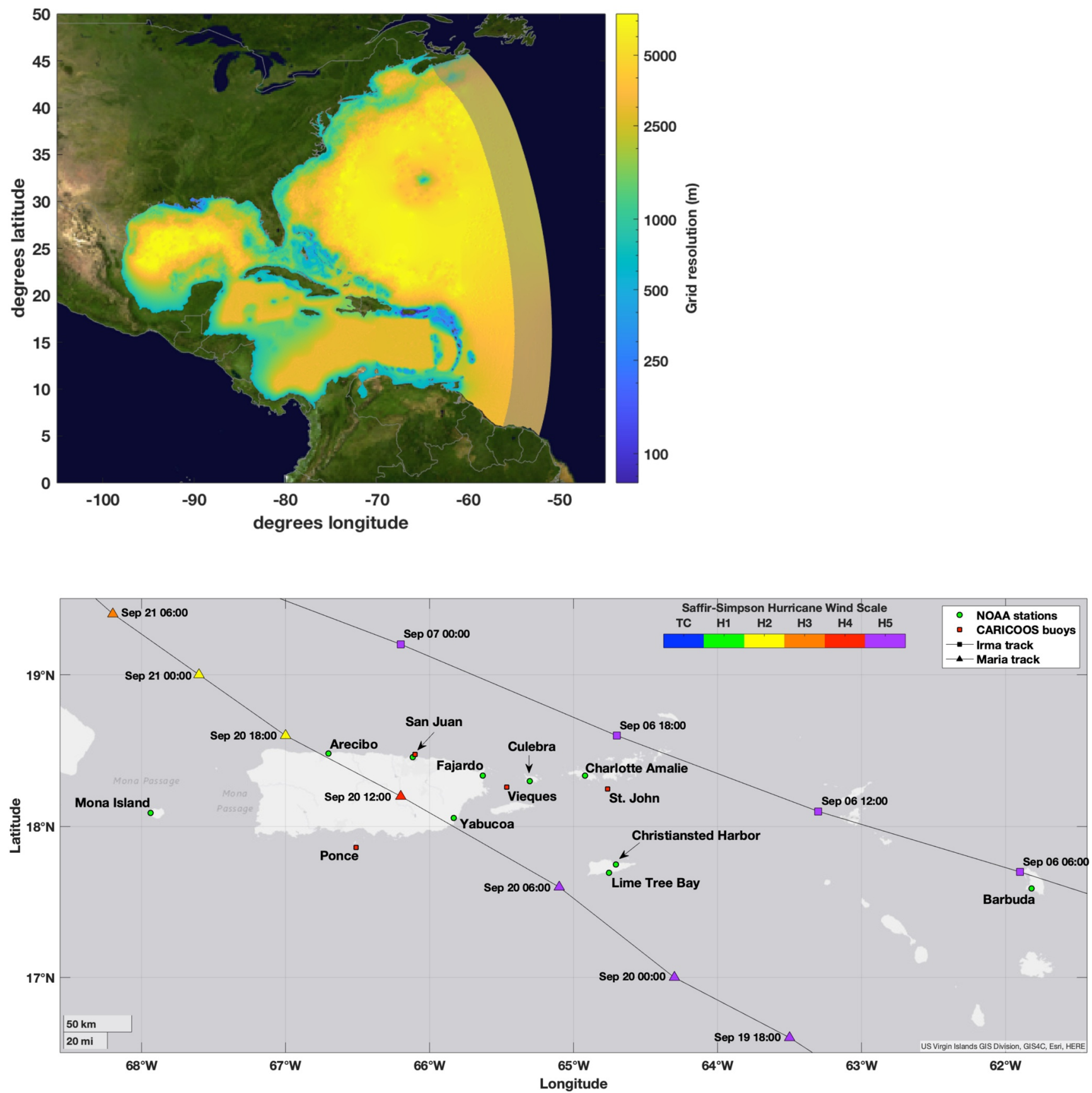

Figure 1. (a) Computational domain with the colors indicating the local mesh resolution (defined as the element circumradius). Grayed area in the vicinity of the open boundary shows the location of the sponge layer. (b) Approximate location of NOAA water level stations (green circles) and CARICOOS wave buoys (red squares). Irma and Maria best tracks from Automated Tropical Cyclone Forecasting System and hurricane category on Saffir-Simpson Hurricane intensity scale.

Within the sponge layer (grayed area in Figure 1a) the depth-integrated baroclinic pressure gradient and momentum dispersion are set to zero. The free surface elevation given by the CESM is added to the tidal elevation solution, while the velocity tidal reference solutions remained unchanged. Atmospheric pressure and 10-m winds are set to their background values of $1,013 \mathrm{hPa}$ and $0 \mathrm{~m} / \mathrm{s}$, respectively.

The 2DBC and BT simulations were conducted over a two-month period beginning on August 1, 2017, where the first month was used for spinning up the baroclinic forcing. These simulations are used to assess 
the quality of the baroclinic and atmospheric forcings as well as the ability of the coupled model to represent the hurricane-induced sea level variations.

\subsection{Numerical Setup: Climate Scenarios}

To compare the hurricane impacts in the present and future climate we force the 2DBC model using the CESM results from the future warming simulation averaged over September 2000-2020 (present-day scenario) and September 2080-2100 (future scenario). We blend the 2017 hurricane wind and sea-level pressure ERA5 data with the mean atmospheric fields of the CESM for September 2000-2020 and 2080-2100 as described above. In this way, we can compare the impact of similar hurricanes in different background conditions (2000-2020 and 2080-2100).

CESM provides projections of the sterodynamic sea-level rise caused by changes in ocean density and circulation. The local sterodynamic sea-level consists of the global-mean thermosteric sea level and the ocean dynamic sea-level components (Gregory et al., 2019; van Westen et al., 2020). The dynamic sea-level, which is a part of the standard output from CESM, was specified at the lateral open boundary. The global-mean thermosteric contribution was calculated by postprocessing as described in van Westen et al. (2020) and amounted to $14.27 \mathrm{~cm}$ in the period from 2000-2020 to 2080-2100. Since the effects of mass loss by glaciers and/or the Antarctic and Greenland ice sheets are not captured by CESM, these were drawn from Church et al. (2013). The contributions are fairly homogeneous on the regional scale and were therefore incorporated into the global-mean thermosteric sea-level rise. The resulting value of $42.79 \mathrm{~cm}$ was included by adjusting the bathymetric depths while keeping a fixed present-day coastline. This configuration is analogous to building vertical walls at the coastline prior to increasing the water depth, thus not allowing new areas to flood. We assume that reefs and mangroves acting as natural barriers will continue to provide dissipation and protection from the nearshore to the shelf edge in the future. The Manning's bottom roughness coefficient $n_{M}$, therefore, was unchanged.

As summarized in Haigh et al. (2020), recent studies project future modifications of the tidal properties due to the ongoing sea level rise and climate change. However, a simulation of global tides with a $2 \mathrm{~m}$ sea-level rise (Pickering et al., 2017) found only minimal changes in the deep-sea tides in the vicinity of the lateral open boundary. We, therefore, assume that the amplitudes and phases of the equilibrium tidal constituents along the open boundary remain unchanged in 2080-2100 compared to 2000-2020. In the climate simulations only equilibrium tidal dynamics is considered, that is, no nodal/satellite corrections are applied.

\subsection{Observation Data and Error Metrics}

For model-data comparison a number of NOAA (U.S. National Oceanic and Atmospheric Administration, https://tidesandcurrents.noaa.gov/) tide gauge and CARICOOS (the IOOS Caribbean Coastal Ocean Observing System, https://www.caricoos.org/) wave stations were selected (cf. Figures 1b and Table 1). Water levels are measured every $6 \mathrm{~min}$, while wave and meteorological data are available at 1 -h time intervals.

The model performance at a particular tide gauge is evaluated by means of three commonly used measures: root-mean-square error, normalized variance of the error $\gamma^{2}$ (Kodaira et al., 2016) and Willmott's index of agreement $d$ (Willmott, 1981); these are defined as

$$
R M S E=\sqrt{\sum_{i=1}^{n} \frac{\left(\zeta_{m}-\zeta_{o}\right)^{2}}{n}},
$$


Table 1

Names and Locations of the NOAA Tide Gauges and CARICOOS Wave Buoys Used for Model Validation

\begin{tabular}{|c|c|c|c|}
\hline \multicolumn{4}{|l|}{ ID } \\
\hline NOAA tide gauges & Station name & Location & $\% \mathrm{QC}$ \\
\hline 1 & Mona Island, PR & $\left(67^{\circ} 56.3^{\prime} \mathrm{W}, 18^{\circ} 05.4^{\prime} \mathrm{N}\right)$ & 100/99/- \\
\hline 2 & Arecibo, PR & $\left(66^{\circ} 42.1^{\prime} \mathrm{W}, 18^{\circ} 28.8^{\prime} \mathrm{N}\right)$ & $78 / 78 / 75$ \\
\hline 3 & San Juan, La Puntilla, San Juan Bay, PR & $\left(66^{\circ} 07.0^{\prime} \mathrm{W}, 18^{\circ} 27.6^{\prime} \mathrm{N}\right)$ & $100 / 95 / 89$ \\
\hline 4 & Yabucoa Harbor, PR & $\left(65^{\circ} 50.0^{\prime} \mathrm{W}, 18^{\circ} 03.3^{\prime} \mathrm{N}\right)$ & $99 /-/ 64$ \\
\hline 5 & Fajardo, PR & $\left(65^{\circ} 37.8^{\prime} \mathrm{W}, 18^{\circ} 20.1^{\prime} \mathrm{N}\right)$ & $65 /-/ 65$ \\
\hline 6 & Culebra, PR & $\left(65^{\circ} 18.1^{\prime} \mathrm{W}, 18^{\circ} 18.1^{\prime} \mathrm{N}\right)$ & $100 /-/-$ \\
\hline 7 & Charlotte Amalie, VI & $\left(64^{\circ} 55.5^{\prime} \mathrm{W}, 18^{\circ} 20.8^{\prime} \mathrm{N}\right)$ & $19 / 19 / 19$ \\
\hline 8 & Lime Tree Bay, St. Croix, VI & $\left(64^{\circ} 45.2^{\prime} \mathrm{W}, 17^{\circ} 41.7^{\prime} \mathrm{N}\right)$ & $64 / 64 / 64$ \\
\hline 9 & Christiansted Harbor, St. Croix, VI & $\left(64^{\circ} 41.9^{\prime} \mathrm{W}, 17^{\circ} 44.8^{\prime} \mathrm{N}\right)$ & $100 /-/-$ \\
\hline 10 & Barbuda, AG & $\left(61^{\circ} 49.2^{\prime} \mathrm{W}, 17^{\circ} 35.5^{\prime} \mathrm{N}\right)$ & $0 / 100 / 17$ \\
\hline \multicolumn{4}{|c|}{ CARICOOS wave buoys } \\
\hline PR1 & Ponce, PR & $\left(66^{\circ} 31.9^{\prime} \mathrm{W}, 17^{\circ} 52.1^{\prime} \mathrm{N}\right)$ & 64 \\
\hline PR2 & San Juan, PR & $\left(66^{\circ} 5.9^{\prime} \mathrm{W}, 18^{\circ} 28.5^{\prime} \mathrm{N}\right)$ & 99 \\
\hline PR3 & Vieques Island, PR & $\left(65^{\circ} 27.9^{\prime} \mathrm{W}, 18^{\circ} 15.7^{\prime} \mathrm{N}\right)$ & 94 \\
\hline VI1 & St. John, VI & $\left(64^{\circ} 45.8^{\prime} \mathrm{W}, 18^{\circ} 14.9^{\prime} \mathrm{N}\right)$ & 99 \\
\hline
\end{tabular}

Note. The last column shows the percentage of the quality controlled water level/mean sea level pressure/wind speed and significant wave height data for September 2017. Note that station Barbuda, AG is not maintained by NOAA and water level data are not verified.

$$
\begin{gathered}
\gamma^{2}=\frac{\operatorname{var}\left(\zeta_{m}-\zeta_{o}\right)}{\operatorname{var}\left(\zeta_{o}\right)} \\
d=1-\frac{\sum_{i=1}^{n}\left(\zeta_{m}-\zeta_{o}\right)^{2}}{\sum_{i=1}^{n}\left(\left|\zeta_{m}-\overline{\zeta_{o}}\right|+\left|\zeta_{o}-\overline{\zeta_{o}}\right|\right)^{2}}
\end{gathered}
$$

where $n$ is the number of observations at each tide gauge within the assessment period and $\zeta_{m}$ and $\zeta_{o}$ refer to the modeled and observed time series, respectively. The temporal mean of the observations is denoted as $\bar{\zeta}_{o}$ and var represents the temporal variance; a more accurate agreement gives a smaller value of $\gamma^{2}$. Willmott's index $d$ describes the relative covariability of modeled and observed values about the observation mean; a value of 1 represents perfect agreement and a value of 0 represents complete disagreement.

\section{September 2017 Model Validation}

\subsection{Atmospheric and Wave Fields}

Figure 2 shows a comparison of September 2017 mean 10-m wind speed and mean sea-level pressure from CESM and ERA5. The mean sea-level pressure from CESM is typically 1-2 hPa higher than that from ERA5. The mean winds from CESM are stronger in the Atlantic and the Caribbean Sea south of $16^{\circ} \mathrm{N}$, while being weaker in the northwest Caribbean and southwest of Puerto Rico and Dominica.

The time series of the CESM and combined CESM + ERA5 sea-level pressure and wind velocity over the period September 2017 are shown at the selected stations in Figure 3. The time series of the blended CESM + ERA5 product is similar to that of ERA5. The quality of the tropical cyclone representation in the 

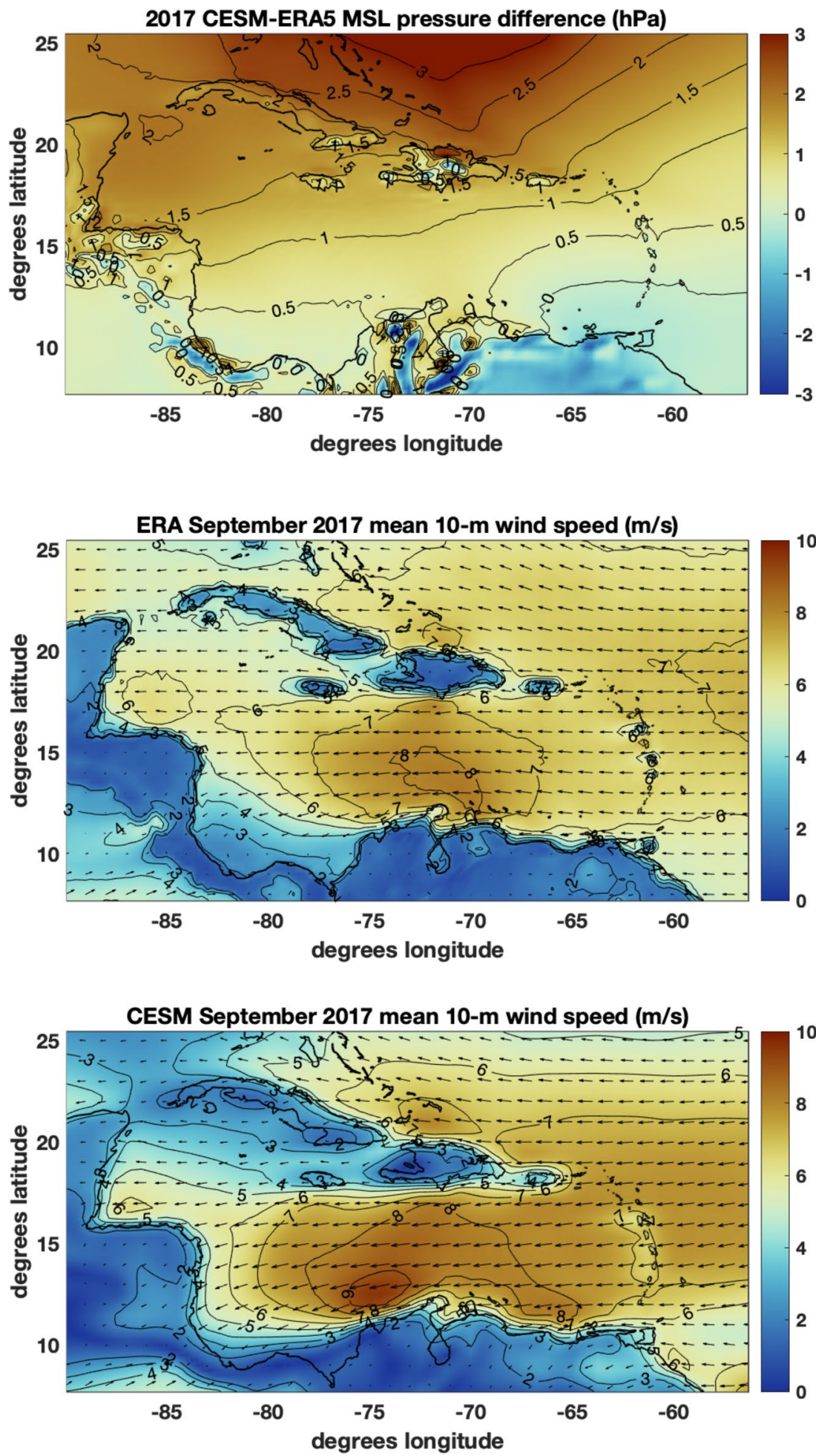

Figure 2. Difference between CESM and ERA5 mean September 2017 sea-level pressure (a); mean September 10-m wind speed drawn from ERA5 (b) and CESM (c). 

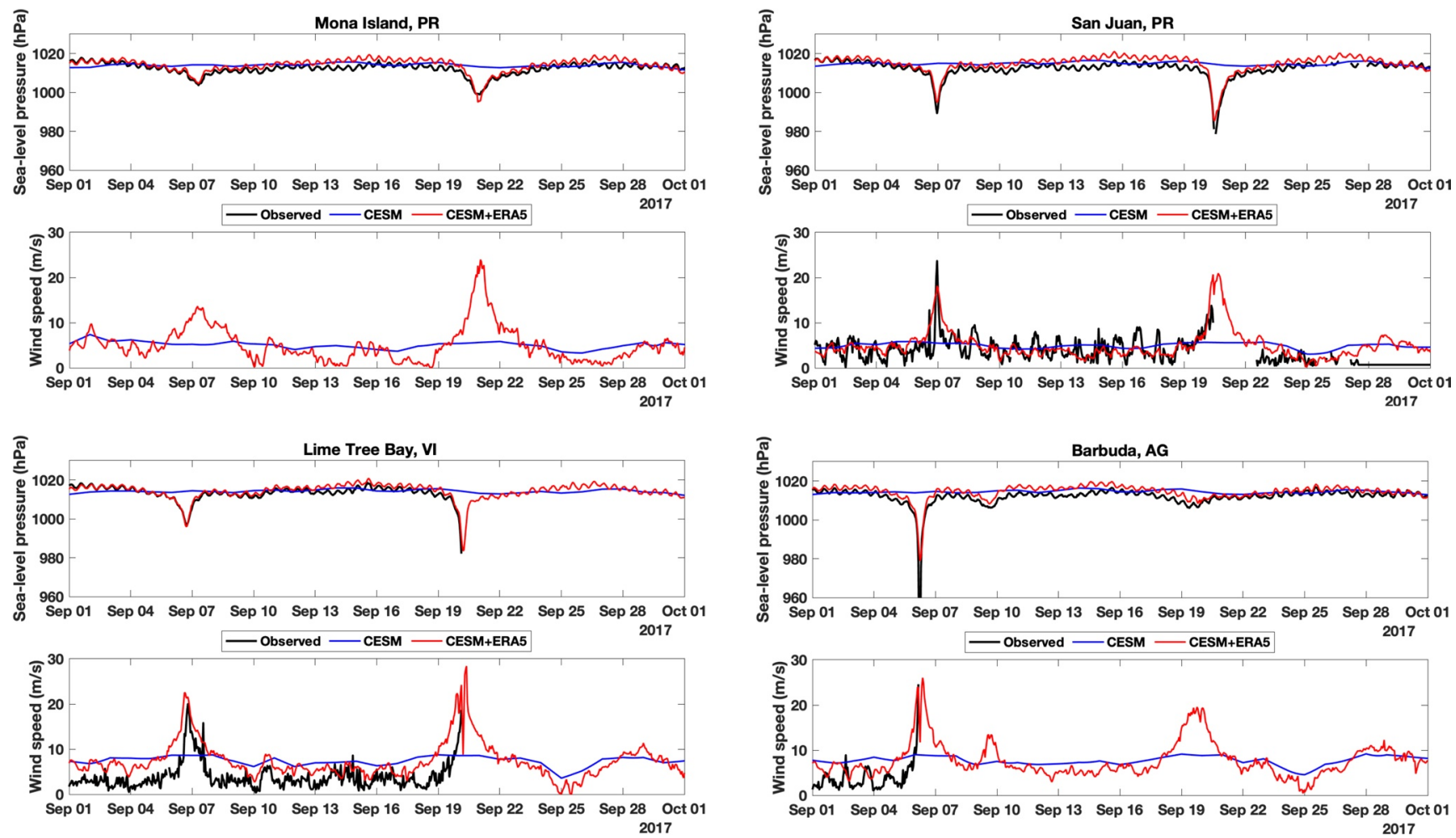

Figure 3. September 2017 sea-level pressure and wind speed at the selected stations from Barbuda to Mona Island as observed (black line), modeled by CESM (blue line) and used to force ADCIRC (red line).

blended product is limited by that of ERA5. Although ERA5 is a large improvement to the previous versions of the ECMWF atmospheric fields, it still tends to underestimate the central pressure deficit and wind speed (Dullaart et al., 2020).

Figure 4 shows the comparison of the significant wave height from the 2DBC model with observations made at the CARICOOS wave buoys. At St John and San Juan stations, model gives good representation of the pre-storm significant wave height, while at Vieques and Ponce it is overestimated. The peak in significant wave height induced by hurricane Irma is underestimated at St John and Viegues, but overestimated at San Juan. While the height of the peak agrees with observations at Ponce station, it is significantly delayed. The height of the Maria induced peak is in very good agreement with the observations at St John station while being underestimated at Vieques and overestimated at San Juan. The Ponce buoy was ripped from its mooring during Hurricane Maria, and it is possible that the highest SWH was not measured.

\subsection{Water Levels}

The $2 \mathrm{DBC}$ and $\mathrm{BT}$ simulations were conducted over a two-month period beginning on August 1, 2017, where the first month was used for spinning-up the baroclinic forcing. A comparison of the modeled and observed sea level time series at four stations around Puerto Rico and the Virgin Islands area is shown in Figure 5. Where available, the modeled time series from Pringle et al. (2019) are also shown. Both BT and 2DBC models are able to capture the primary surge processes. As shown by Joyce et al. (2019), the storm surge affecting the Virgin Islands was predominantly driven by the inverted barometer response to the central pressure deficit. As a result, overestimation of the tropical cyclone central pressure in ERA5 (cf. Figure 3), contributes to an underestimation of the surge at Barbuda, and other stations in the direct vicinity of the cyclone track. The storm surge values do not differ significantly between the BT and 2DBC models. The peak water levels are better represented in the $2 \mathrm{DBC}$ model primarily because of the baro- 

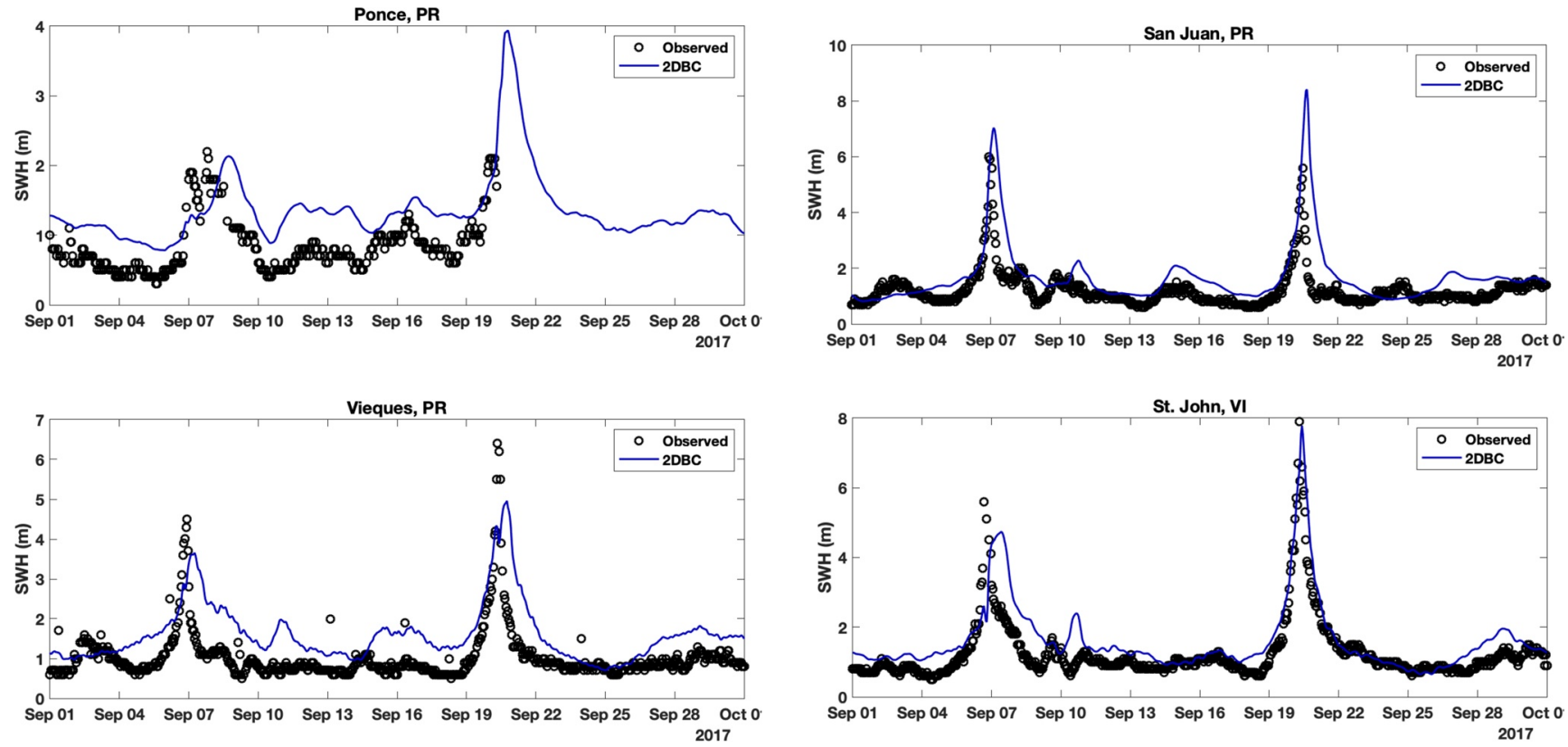

Figure 4. Observed versus modeled significant wave height at the CARICOOS wave buoys for September 2017.

clinicity induced pre-storm offset in the background water levels. The offset is related to the thermo-steric seasonal cycles affected by the large-scale dynamics of the ocean.The error metrics given by Equation 7 of the BT and 2DBC model simulations for the full signal including tides and for the non-tidal residual at the tide gauges are shown in Figure 6. The non-tidal residual was calculated by subtracting the predicted tide from the measured (simulated) sea level time-series. The tidal prediction was conducted by means of UTide tidal harmonic analysis software (Codiga., 2011) requesting the same 8 tidal constituents as used to force the model. Inclusion of the ocean baroclinicity results in a smaller root-mean-square error of the full signal at nine out of 10 stations in the Puerto Rico - Virgin Islands (PRVI) region; the domain
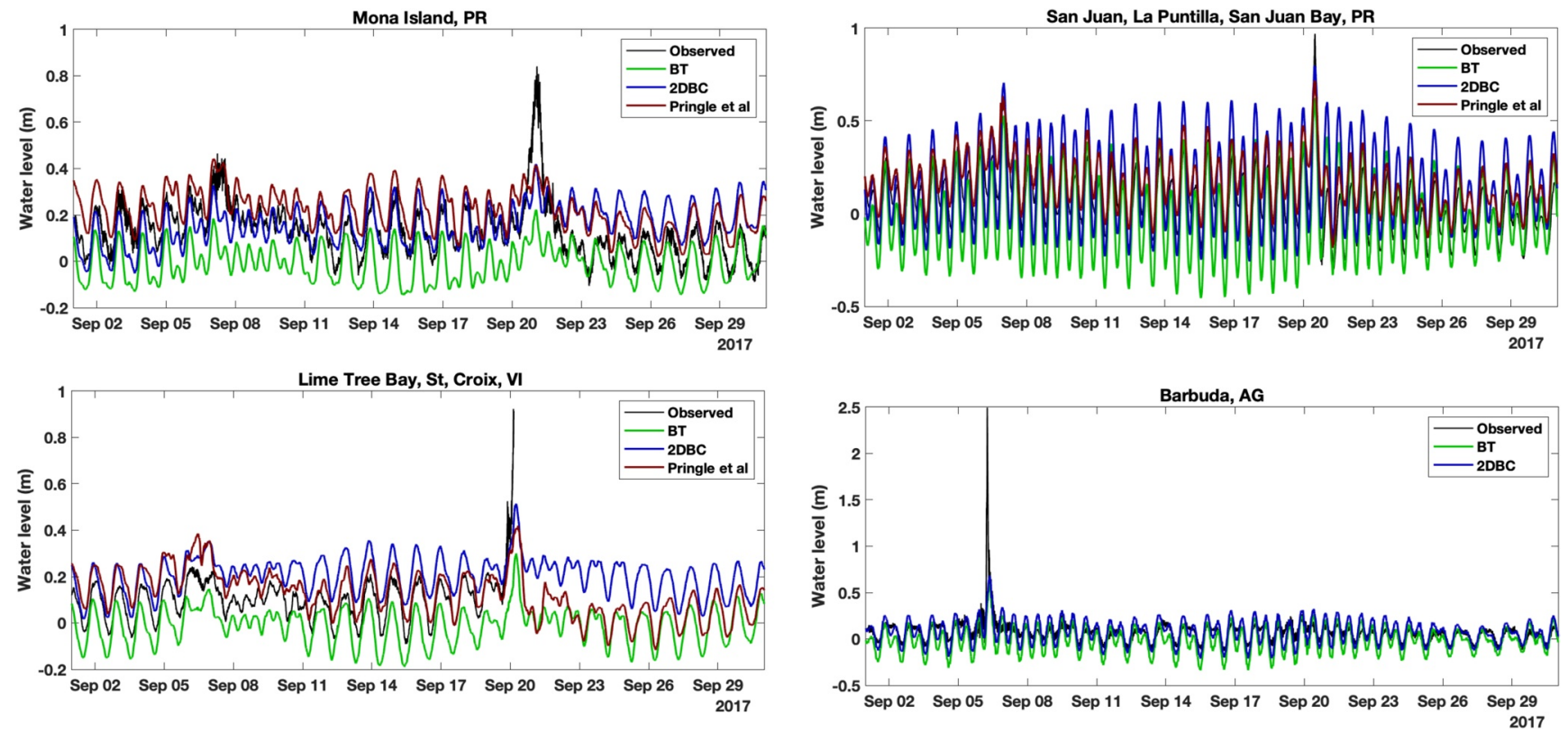

Figure 5. Observed versus model water-level timeseries at the selected stations from Barbuda to Mona Island, Puerto Rico. 

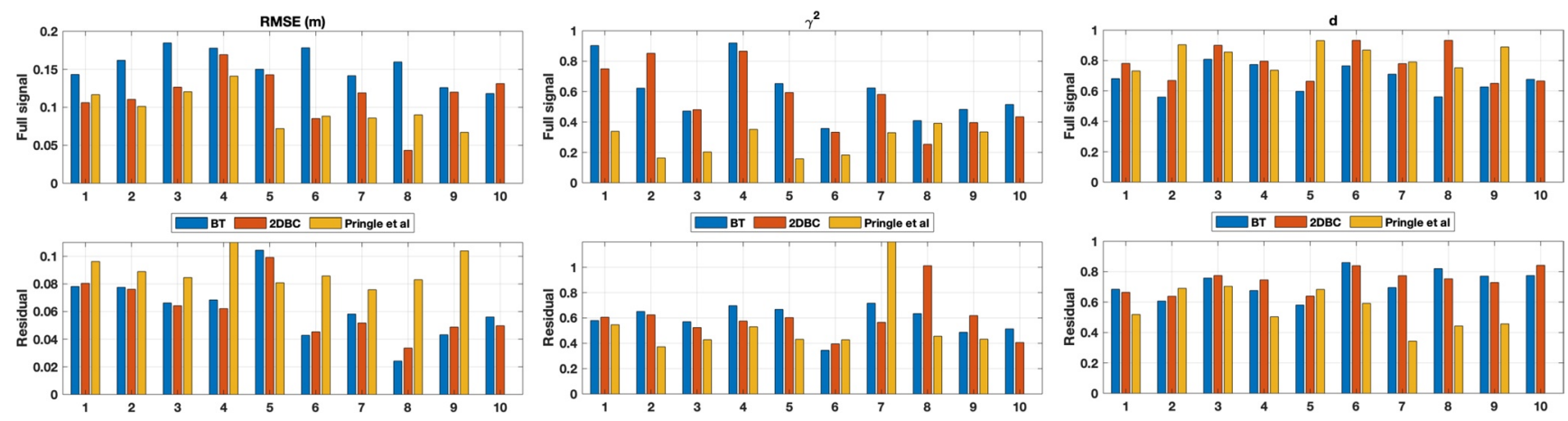

Figure 6. (a) Root-mean-square errors, (b) normalized variance, and (c) Index of agreement of the full signal (top) and the non-tidal residual (bottom) at the selected stations.

averaged error is reduced from 15 to $11 \mathrm{~cm}$. The normalized variance of the full signal $\gamma^{2}$ is reduced at 8 stations; the mean value decreased from 0.59 to 0.55 . Willmott's index of agreement is increased at 9 stations; averaged over all the tide gauges $d$ increased from 0.68 to 0.78 . The residual RMSE, $\gamma^{2}$ and the Willmott's index of agreement of the baroclinically-coupled model run improved at 6 stations out all belonging to the PRVI area.

Based on the error metrics of the full signal, the model of Pringle et al. (2019) baroclinically coupled to the operational data-assimilated Global Ocean Forecast System 3.1 (Metzger et al., 2017) outperforms the one presented here. The difference between the models is especially noticeable at the stations where a water-level set down following the storm passage was observed (e.g., Lime Tree Bay, VI station, Figure 5). This is not surprising since tropical storms and, therefore mixing of the warm surface waters with colder waters below the thermocline by the storm passage, are not directly simulated by CESM (no data-assimilation is used). Nevertheless, coupling to CESM enhanced the ability of the model to represent water level variations and improved its skill compared to the BT model. The $2 \mathrm{DBC}$ model, therefore, is better suited for studying the future changes in the hurricane-induced extreme water levels than the BT one.

\section{Changes in the Mean Fields and Hurricane Impacts}

Here we use the 2DBC model results to assess projected changes in the local mean dynamic sea level (MDSL), tidal range, wave pattern as well as in hurricane-induced water levels. The mean September 20002020 dynamic sea level is shown in Figure 7a, and the difference between the 2080-2100 and 2000-2020 periods in Figure 7b. Note that the global mean sea level of 2080-2100 is offset by $42.79 \mathrm{~cm}$ from that of 2000-2020 to account for the global-mean thermosteric sea level rise and effects of mass addition. The positive (negative) MDSL difference, thus means above (bellow) average sea-level rise. Although the difference pattern shown in Figure $7 \mathrm{~b}$ is quite inhomogeneous, the model projects up to a $5-10 \mathrm{~cm}$ lower (higher)
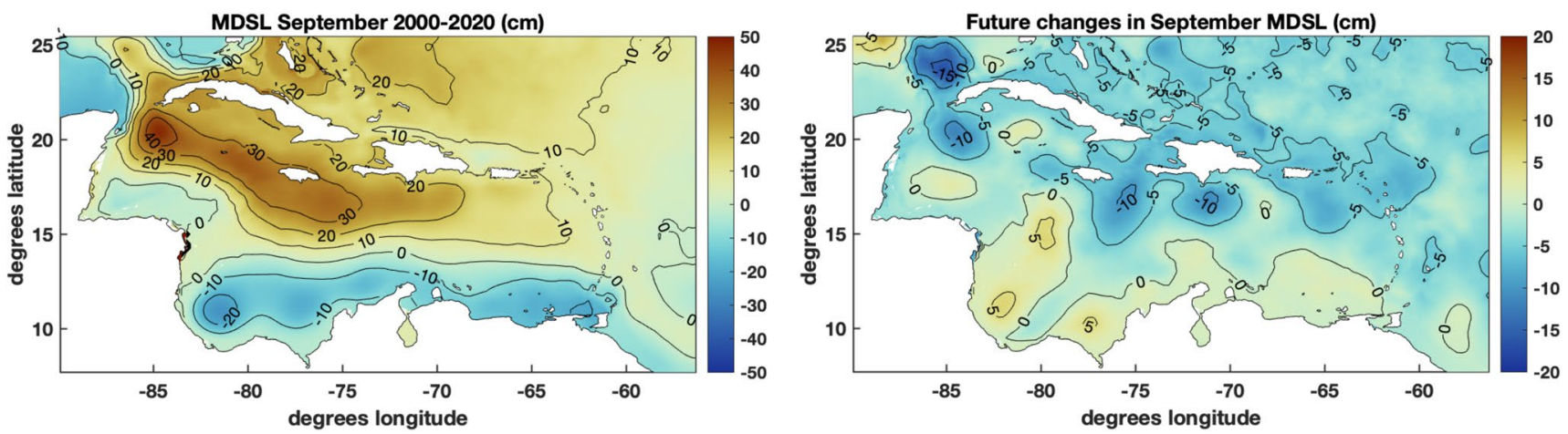

Figure 7. (a) Mean September 2000-2020 dynamic sea level (cm) and (b) the projected change for September 2080-2100. Note that the global mean sea-level of $2080-2100$ is offset by $42.79 \mathrm{~cm}$ from that of $2000-2020$. 


\section{Table 2}

September Mean Dynamic Sea Level (MDSL), Mean Equilibrium Tidal Range (MTR), Mean and Peak Significant Wave Height, Storm Tide and Storm Surge for the 2000-2020 (Present) and 2080-2100 (Future) Cases

\begin{tabular}{|c|c|c|c|c|c|c|c|c|}
\hline \multirow[b]{2}{*}{ ID } & \multicolumn{2}{|c|}{$\operatorname{MDSL}(\mathrm{cm})$} & \multicolumn{2}{|c|}{$\operatorname{MTR}(\mathrm{cm})$} & \multicolumn{2}{|c|}{ Storm tide $(\mathrm{cm})$} & \multicolumn{2}{|c|}{ Storm surge $(\mathrm{cm})$} \\
\hline & Present & Future & Present & Future & Present & Future & Present & Future \\
\hline & & & & & Irma/Maria & Irma/Maria & Irma/Maria & Irma/Maria \\
\hline 1 & 10.7 & 5.1 & 20.5 & 20.6 & $21.7 / 22.0$ & $22.2 / 21.3$ & $11.0 / 19.7$ & $11.5 / 19.5$ \\
\hline 2 & 9.9 & 4.0 & 57.9 & 57.8 & $43.3 / 55.5$ & $43.5 / 54.5$ & $20.1 / 33.1$ & $20.6 / 32.6$ \\
\hline 3 & 9.0 & 3.1 & 57.3 & 57.1 & $39.7 / 42.9$ & $40.2 / 42.2$ & $22.2 / 32.0$ & $22.5 / 31.5$ \\
\hline 4 & 10.5 & 5.0 & 21.6 & 21.5 & $16.3 / 36.6$ & $16.4 / 36.2$ & $14.9 / 30.2$ & $15.1 / 30.2$ \\
\hline 5 & 9.4 & 3.6 & 46.5 & 46.3 & $33.4 / 41.4$ & $34.0 / 40.3$ & $16.9 / 35.2$ & $17.4 / 35.1$ \\
\hline 6 & 9.9 & 4.4 & 28.9 & 28.9 & $25.4 / 35.2$ & $26.2 / 34.2$ & $24.4 / 35.4$ & $24.6 / 34.9$ \\
\hline 7 & 11.1 & 5.7 & 21.5 & 21.4 & $25.6 / 45.0$ & $26.1 / 44.1$ & $31.3 / 41.7$ & $31.9 / 41.2$ \\
\hline 8 & 12.3 & 6.8 & 21.2 & 21.0 & $19.0 / 35.8$ & $19.4 / 35.3$ & $18.5 / 31.7$ & $18.7 / 31.7$ \\
\hline 9 & 12.3 & 6.7 & 21.4 & 21.4 & $23.3 / 36.6$ & $23.6 / 35.9$ & $20.2 / 32.5$ & $20.5 / 31.9$ \\
\hline \multirow[t]{2}{*}{10} & 8.1 & 1.4 & 27.8 & 27.9 & $49.1 / 21.4$ & $48.0 / 20.6$ & $47.2 / 13.3$ & $46.1 / 12.7$ \\
\hline & & \multicolumn{3}{|c|}{ Mean SWH (m) } & & \multicolumn{2}{|c|}{ Peak SWH (m) } & \\
\hline ID & & Present & & Fut & & Pres & & Future \\
\hline PR1 & & 0.74 & & & & 1.72 & & $1.74 / 4.40$ \\
\hline PR2 & & 0.72 & & & & 5.83 & & $5.72 / 6.52$ \\
\hline PR3 & & 0.75 & & & & $3.29 /$ & & $3.28 / 4.42$ \\
\hline VI1 & & 0.94 & & & & $4.65 /$ & & $4.55 / 8.09$ \\
\hline
\end{tabular}

Note. MDSL is referenced to the global mean sea level of the respective run (Note: The global mean sea level of $2080-2010$ is offset by $42.79 \mathrm{~cm}$ from that of 2080-2100). Storm tide values are referenced to the MSL at the station from the respective case. Values induced by the two different hurricanes (Irma/Maria) are provided (separated by a slash). Station ID as in Table 1

than the average mean sea-level rise in the northeast (south and southwest). The September mean dynamic sea-levels are projected to become $5-7 \mathrm{~cm}$ lower in the future at all stations shown in Figure $1 \mathrm{~b}$, see Table 2. As shown by van Westen et al. (2020), changes in the local sterodynamic sea-level deviations from the global-mean thermosteric sea level are related to the projected reduction in the strength of the Atlantic Meridional Overturning Circulation and the associated decrease in eddy activity and strength.

Figure 8a shows mean significant wave heights (SWH) for September 2000-202020 with the difference between 2080-2100 and 2000-2020 results in Figure 8b. The mean SWH varies between 0.5-1 m in the west, 1-2 $\mathrm{m}$ in the center, and 0.75-1.5 $\mathrm{m}$ east of the domain. Since Greater and Lesser Antilles act as obstacles, which do not allow the Atlantic Ocean waves to fully penetrate the Caribbean Sea, the surface waves are
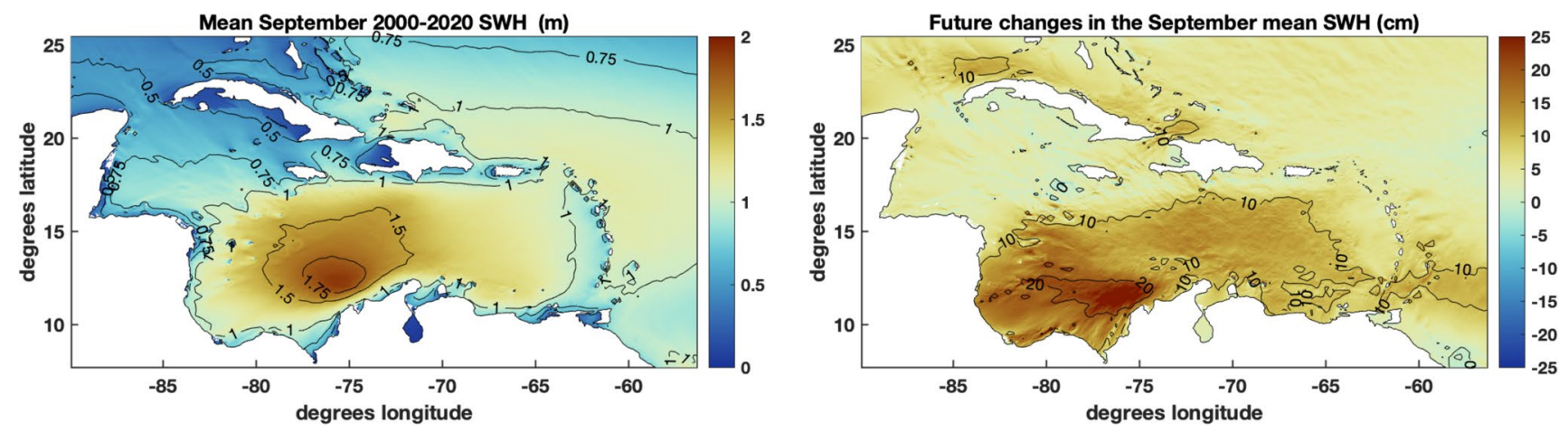

Figure 8. Mean significant wave height (m) for September 2000-2020 (a) and (b) the projected change for September $2080-2100$. 

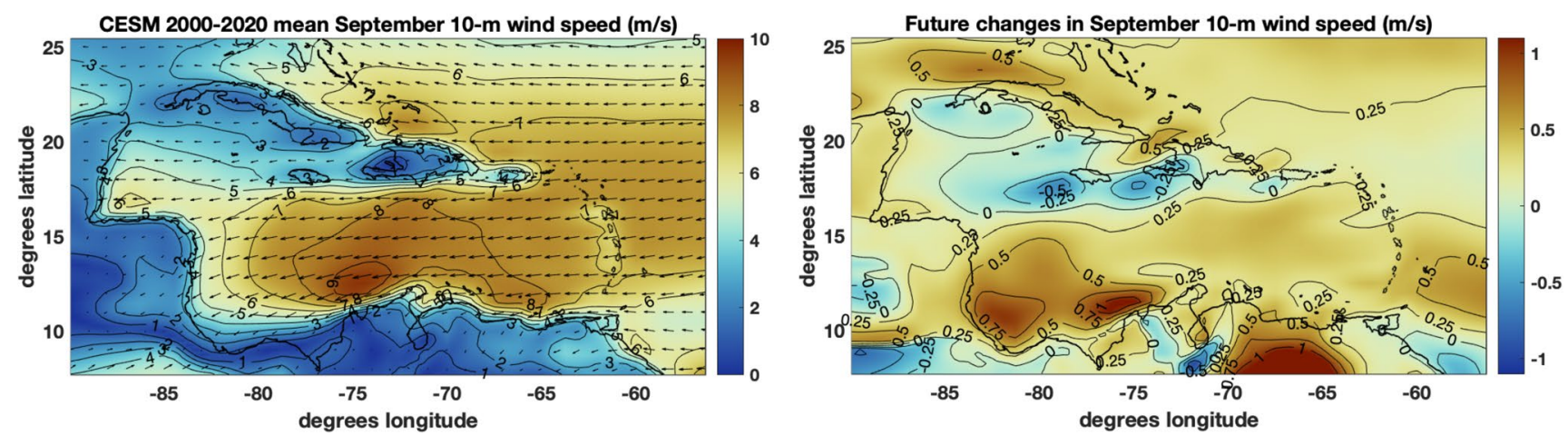

Figure 9. Mean 10-m wind speed (m/s) and direction for September 2000-2020 (a) and (b) difference between future (2080-2100) and present (2000-2020) wind speed.

mostly generated locally. The model projects an overall future increase of the September SWH in the Caribbean Sea, as also shown by, for example, Hemer et al. (2013) and Webb et al. (2018). The largest increase of approximately $25 \mathrm{~cm}$ occurs in the Colombia Basin. In the Venezuela Basin, the mean SWH is projected to increase by $10-15 \mathrm{~cm}$, while in Grenada Basin and Gulf of Honduras changes will not exceed $5 \mathrm{~cm}$. These changes in the mean SWH match in location with the projected increase in 10-m wind velocity magnitude (cf. Figure 9). The location of the maximum wave heights matches the location of the Caribbean Low Level Jet and Trade Winds. Wolf and Woolf (2006) have shown that hurricanes generated significant wave heights strongly depend on the intensity of the prevailing winds. Only little changes in the strength of the synoptic winds are projected for the areas affected by the 2017 Irma and Maria hurricanes. As a result, no significant changes in the SWH are projected.

The mean tidal range (MTR), estimated using amplitudes and phases of the eight major tidal constituents, is shown in Figure 10a for September 2000-2020 with again the difference between the future and present cases in Figure 10b. The MTR was calculated as a difference between the mean of all tidal high waters (HW) and the mean of all low waters (LW) from a year-long tidal prediction time series. Heights of HWs and LWs were extracted by locating the turning points of the time series reconstructed from 8 tidal constituents (Q1, $\mathrm{O} 1, \mathrm{P} 1, \mathrm{~K} 1, \mathrm{~N} 2, \mathrm{M} 2, \mathrm{~S} 2, \mathrm{~K} 1)$. The September specific values of the constituents were obtained using the ADCIRC build-in harmonic analysis capability from the modeled September water level time series.

Tides in the Caribbean Sea are characterized by a so-called micro-tidal range, where the mean tidal range does not exceed $50 \mathrm{~cm}$ in the major part of the Sea. Only at the Nicaraguan shelf, the MTR is larger than $1 \mathrm{~m}$ (Figure 10a) due to a regional resonance in M2 component tide (Kjerfve, 1981). Equilibrium tidal dynamics is affected by the increase in water depth via the reduction in dissipation at the bottom. The propagation speed of the tidal wave is also altered causing a spatial reorganization of the amphidromic system. Additionally, Pringle et al. (2019) has shown that M2 tide around PRVI is sensitive to ocean baroclinicity due to internal tide conversion. The future mean equilibrium tidal range is projected to
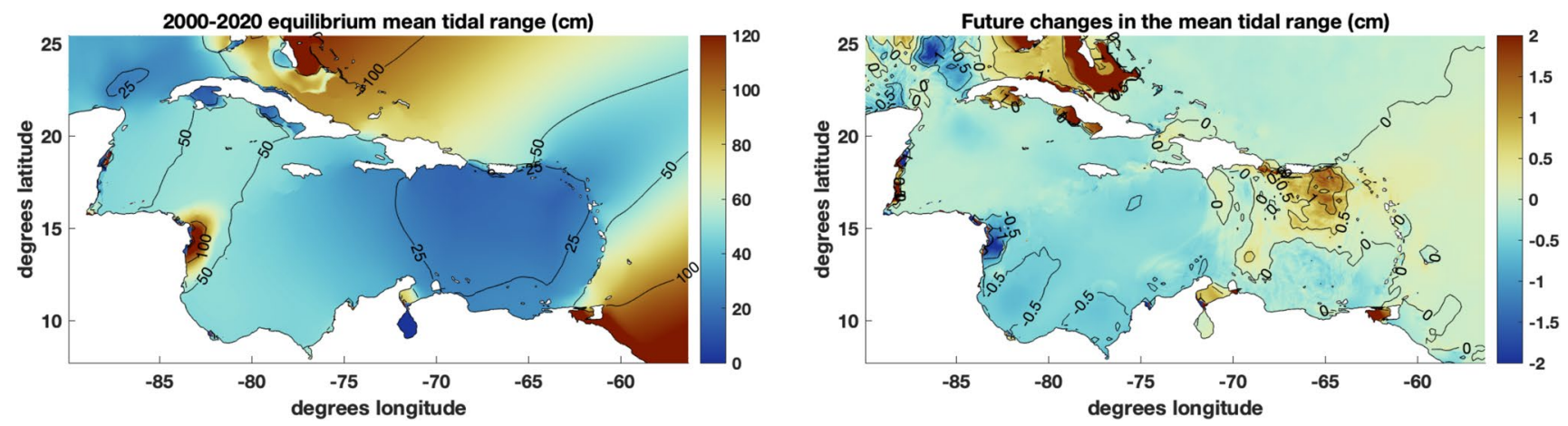

Figure 10. Mean equilibrium tidal range (cm) for (a) September 2000-2020 and (b) the projected change for September 2080-2100. 
decrease in the west and the southwest Caribbean and to increase in the eastern part. The projected changes, however, do not exceed $2-3 \mathrm{~cm}$. No significant changes in the mean equilibrium tidal range for the stations around Puerto Rico and the Virgin Islands (used in this study) are projected (cf. Table 2).

The strong winds and low atmospheric pressure associated with tropical storms usually lead to significant anomalies in the tide. The difference between the actual tide as influenced by a meteorological disturbance (storm tide) and the predicted astronomical tide is called the storm surge. A gradual rise in the tide level often begins more than $24 \mathrm{~h}$ before, while the peak storm surge usually occurs within an hour or two after the storm makes its nearest approach to the station. The peak storm tide (maximum hurricane-induced water level), however, can occur several hours later, if the surge peak occurs near the time of normal low water.

In Table 2, also the 2DBC-model results regarding the impacts of the September 2017 hurricanes, as measured through the peak water levels (peak storm tide) and the peak storm surge, at the stations for both 2000-2020 and 2080-2100 situations are listed. The peak water levels during the hurricane passage (storm tide levels) are referenced to the September mean sea-level at the station. Peak storm-tide and storm-surge levels induced by Irma and Maria are both provided (separated by a slash). For all of the stations, the differences between the present and future storm-surges and peak water levels (relative to the MSL at the station) do not exceed 1-2 cm. As the atmospheric forcing was created in such a way that the central pressure deficit in the future remained the same, the pressure-driven surge, which was the main contribution to the storm water levels, did not change. The differences in surge levels between the present and future scenarios are hence mainly due to changes in the MSL, tidal, and wind-driven contributions.

The Caribbean Sea is known to be an eddy-rich region (Chelton et al., 2007), with eddy-related sea level anomalies reaching locally a few tens of centimeters (Andrade \& Barton, 2000; Alvera-Azca'rate et al., 2009). Caribbean tides are subject to significant long-term modulations causing up to $23.5 \%$ change in the tidal range (Torres \& Tsimplis, 2011). To evaluate whether the eddy-related sea-level variability and tidal modulation can significantly influence the TC impact projections, we also considered a single-year scenario (see Appendix A). We compared the MDSL, SWH, MTR projections, and hurricane impacts under 2017 and 2100 background conditions. Under the single-year scenario, projected MDSL changes are generally of the same magnitude ( $4-8 \mathrm{~cm}$ vs. $5-7 \mathrm{~cm}$ ) as that of 20-years mean scenario but have different signs at the Mona Island station. The single-year projected changes in the mean tidal range do not exceed $4 \mathrm{~cm}$ at any of the stations. The storm-surge heights caused by the 2017 Irma and Maria hurricanes are projected to be slightly lower (typically by $2-4 \mathrm{~cm}$ ) in 2100 than in 2017. At the majority of the stations around Puerto Rico and the Virgin Islands, the storm-tide levels are predicted to be up to $10 \mathrm{~cm}$ lower than present peak water levels (relative to the local mean sea level) when comparing the 2017 and 2100 background climate conditions. The single-year scenarios, thus, predict larger changes in the mean fields and hurricane impacts than the 20-years mean scenarios. The changes are, nevertheless, small compared to the projected global mean sea-level rise.

\section{Summary and Discussion}

In 2017, the Atlantic Ocean experienced an extremely intense hurricane season which caused unprecedented levels of destruction across the Caribbean (Quarless, 2018). Dominica and Barbuda were most severely devastated and many other Caribbean islands including Puerto Rico, Virgin Islands, and Saint Martin suffered serious damage. Some islands, including Saint Martin, were affected by two major hurricanes, Irma and Maria, which followed almost identical tracks within two weeks. While it is uncertain whether the ongoing climate change will lead to more intense tropical storms in the future, increasing development of the coastal zones clearly increases the destructive potential of hurricanes (Emanuel, 2005). It is, therefore, important to assess how other aspects of climate change will influence the risk of the hurricane-induced coastal flooding regardless of possible changes in the tropical cyclone activity.

Here we use a high-resolution numerical model to evaluate the future impacts of the present-day tropical cyclones on the Caribbean region. Using the approach of Pringle et al. (2019), we developed the baroclinic coupling of ADCIRC + SWAN to an ocean-eddying version of the Community Earth System Model, referred to as the 2DBC model. The coupling strategy allows us to take into account not only the projected global sea-level rise but also the local effects of the future changes in the large-scale ocean and atmospheric 
circulation. It was shown that the inclusion of baroclinicity improves the model skill in September 2017 (Willmott's index of agreement) at 9 out of 10 stations, compared to the barotropic 2D model (referred to BT in the paper). This improvement is mostly caused by the reduction of the pre-storm offset in the background water levels. The offset is related to baroclinically induced variations which include thermo-steric seasonal cycles affected by the large-scale dynamics of the ocean.

The water level at the coast results from the interaction between the mean sea level, tides, atmospheric (pressure and wind driven) surge, and wave setup, summarized in, for example, Idier et al. (2019). As shown by Melet et al. (2018), wave contribution to coastal water levels is most important in the areas of strong winds. Projected intensification of prevailing easterly winds and the associated increase in the wave activity can, therefore, make additional contributions to regional sea-level rise, coastal erosion, and flooding by increased wave setup in the Southern Caribbean. The central pressure deficit, which according to Joyce et al. (2019) contributed most to the surges in 2017, does not change between the climate scenarios considered here and is independent of water depth. The effect of wind on the storm surges is strongly dependent on the geometry of the basin and continental shelf. Generally, the same wind forcing (surface stress) is less effective at dragging water and produces a smaller surge when the water depth is larger (Resio \& Westerink, 2008). The future increase in the water depths is, therefore, likely to cause smaller than present-day wind-driven surges, all else being equal. The increased (decreased) tidal range would lead to a higher (lower) peak water level if the hurricane passage coincided with the high tide and a lower (higher) during the low tide, all else being equal. Combination of the above with projected slower than average sea-level rise results only in minor changes (typically less than $2 \mathrm{~cm}$ ) in the future stormsurge heights around Puerto Rico and Virgin Islands (caused by the 2017 Irma and Maria hurricanes) when comparing the present (2000-2020) and future (2080-2100) background climate conditions.

Although only small changes in storm surge levels in the Northeast Caribbean are projected, the impact of the surge on a specific shore region can be substantially different in the future. The 2DBC model projects no increased risk of hurricane-induced flooding provided that hurricane intensity remains at the present-day level and the Caribbean Islands are made resilient to sea-level rise. Specifically, we assumed hard engineering efforts maintaining the present-day shoreline location since coastal recession would lead to dramatic socio-economic impacts (Simpson et al., 2010). Additionally, we assumed that vegetated foreshore ecosystems, coral reefs, and seagrass meadows will remain healthy. Coral reefs sheltering tropical bays and lagoons provide favorable conditions for the growth of seagrass. Seagrass meadows minimize erosion of sandy beaches by stabilizing the sediment and dissipating waves both during calm and hurricane conditions (James et al., 2019, 2020). Healthy vegetated foreshore ecosystems, therefore, play an important role in mitigating coastal flooding caused by natural hazards and increases the resistance of coastal areas to storm surges. The ability of seagrass to withstand the sea-level rise strongly depends on the response of coral reefs to climate change (Keyzer et al., 2020). If coral reefs and, consequently, seagrass meadows cannot keep up with increasing sea-level, the extent of near-shore flooding during storm events will be significantly increased. If both ecosystems remain resilient under climate change and hurricane activity will not change, global sea-level rise remains the main coastal flood risk factor in the Northeast Caribbean.

\section{Appendix A: 2100 - 2017 Changes in the Mean Fields and Hurricane Impacts}

In this section, we compare actual impacts of the 2017 Irma and Maria tropical storms to that of a September specific warming scenario for the year 2100. The projected changes in the mean dynamic sea level, significant wave height, and tidal range between 2017 and 2100 are also shown. The 2017 results are drawn from the 2DBC model run described in Section 3.1. The 2100 model is forced as in Section 3.2, but using the CESM results from the future warming simulation over the 2-month period August-September, the year 2100. As before, the global-mean thermosteric contribution was calculated by postprocessing and amounted to $17.26 \mathrm{~cm}$ in the period from 2017 to 2100 . The effects of mass loss by glaciers and/or the Antarctic and Greenland ice sheets are drawn from Church et al. (2013) were incorporated into the global-mean thermosteric sea-level rise. The resulting value of $76.63 \mathrm{~cm}$ was included by adjusting the bathymetric depths while keeping a fixed present-day coastline. Additionally, the long-term tidal variability is considered. 


\section{Table A1}

September Mean Sea Level (MDSL), Mean Tidal Range (MTR), Mean and Peak Significant Wave Height, Storm Tide and Storm Surge for the 2017 and 2100 Cases

\begin{tabular}{|c|c|c|c|c|c|c|c|c|}
\hline \multirow[b]{3}{*}{ ID } & \multicolumn{2}{|c|}{$\operatorname{MDSL}(\mathrm{cm})$} & \multicolumn{2}{|c|}{$\operatorname{MTR}(\mathrm{cm})$} & \multicolumn{2}{|c|}{ Storm tide $(\mathrm{cm})$} & \multicolumn{2}{|c|}{ Storm surge $(\mathrm{cm})$} \\
\hline & \multirow[b]{2}{*}{2017} & \multirow[b]{2}{*}{2100} & \multirow[b]{2}{*}{2017} & \multirow[b]{2}{*}{2100} & \multirow{2}{*}{$\frac{2017}{\text { Irma/Maria }}$} & 2100 & \multirow{2}{*}{$\frac{2017}{\text { Irma/Maria }}$} & \multirow{2}{*}{$\frac{2100}{\text { Irma/Maria }}$} \\
\hline & & & & & & Irma/Maria & & \\
\hline 1 & 3.6 & 11.8 & 19.5 & 23.0 & $20.6 / 24.2$ & $17.2 / 16.5$ & $10.7 / 19.0$ & $10.8 / 15.8$ \\
\hline 2 & 12.6 & 7.1 & 59.3 & 56.2 & $55.0 / 63.9$ & $48.6 / 62.5$ & $21.1 / 33.0$ & $20.0 / 30.3$ \\
\hline 3 & 11.2 & 6.2 & 58.7 & 55.6 & $56.7 / 64.3$ & $45.9 / 56.8$ & $23.7 / 31.0$ & $21.2 / 29.1$ \\
\hline 4 & 12.1 & 8.2 & 19.6 & 23.4 & $20.3 / 31.2$ & $16.3 / 28.9$ & $17.1 / 29.5$ & $15.6 / 26.3$ \\
\hline 5 & 12.1 & 7.5 & 47.5 & 45.1 & $42.5 / 59.9$ & $42.9 / 49.6$ & $21.0 / 34.9$ & $18.8 / 32.0$ \\
\hline 6 & 11.5 & 6.9 & 29.6 & 29.2 & $35.3 / 37.4$ & $30.7 / 28.5$ & $26.3 / 31.2$ & $25.4 / 29.8$ \\
\hline 7 & 12.2 & 6.8 & 19.4 & 23.4 & $32.1 / 38.9$ & $28.1 / 32.1$ & $31.7 / 34.5$ & $31.6 / 32.4$ \\
\hline 8 & 13.3 & 4.6 & 19.1 & 22.8 & $17.6 / 30.9$ & $20.2 / 21.0$ & $21.1 / 31.3$ & $19.8 / 29.5$ \\
\hline 9 & 13.1 & 5.2 & 19.6 & 23.1 & $15.3 / 34.6$ & $26.3 / 26.6$ & $22.5 / 35.8$ & 20.9/33.6 \\
\hline \multirow[t]{2}{*}{10} & 15.0 & 6.9 & 28.3 & 28.5 & $58.1 / 25.4$ & $52.2 / 20.3$ & $42.8 / 10.9$ & $41.0 / 9.5$ \\
\hline & & \multicolumn{4}{|c|}{ Mean SWH (m) } & \multicolumn{3}{|c|}{ Peak SWH (m) } \\
\hline ID & \multicolumn{3}{|c|}{2017} & \multicolumn{2}{|r|}{2100} & \multicolumn{2}{|c|}{2017} & 2100 \\
\hline PR1 & \multicolumn{3}{|c|}{1.27} & \multicolumn{2}{|r|}{1.29} & \multicolumn{2}{|c|}{$3.65 / 4.96$} & $3.90 / 4.70$ \\
\hline PR2 & \multicolumn{3}{|c|}{1.55} & \multicolumn{2}{|r|}{1.61} & \multicolumn{2}{|c|}{$7.03 / 8.41$} & $7.88 / 7.89$ \\
\hline PR3 & \multicolumn{3}{|c|}{1.49} & \multicolumn{2}{|r|}{1.55} & \multicolumn{2}{|c|}{$2.13 / 3.93$} & $2.24 / 3.76$ \\
\hline VI1 & \multicolumn{3}{|c|}{1.54} & \multicolumn{2}{|r|}{1.56} & \multicolumn{2}{|c|}{$4.74 / 7.78$} & $4.57 / 7.18$ \\
\hline
\end{tabular}

Note. MDSL is referenced to the global mean sea level of the respective run (Note: The global mean sea level of 2100 is offset by $76.63 \mathrm{~cm}$ from that of 2017 ). Storm tide values are referenced to the MSL at the station from the respective case. Values induced by the two different hurricanes (Irma/Maria) are provided (separated by a slash).

Comparison of the mean September 2100 and 2017 dynamic sea level shown in Figure A1 leads to the same general conclusion as the comparison of the 20-years mean present and future results (cf. Figure 7): weaker dynamic sea level extremes in the future. The exact amount of the dynamic sea level change at a specific location can, however, differ considerably between the 20-years mean and single-year runs due to eddying nature of the region. At the stations shown in Figure 1b, 2100-2017 mean dynamic sea level change is larger than the 20-years mean change (cf. Tables 2 and A1). For Mona Island (station 2) also the direction of the change differs.
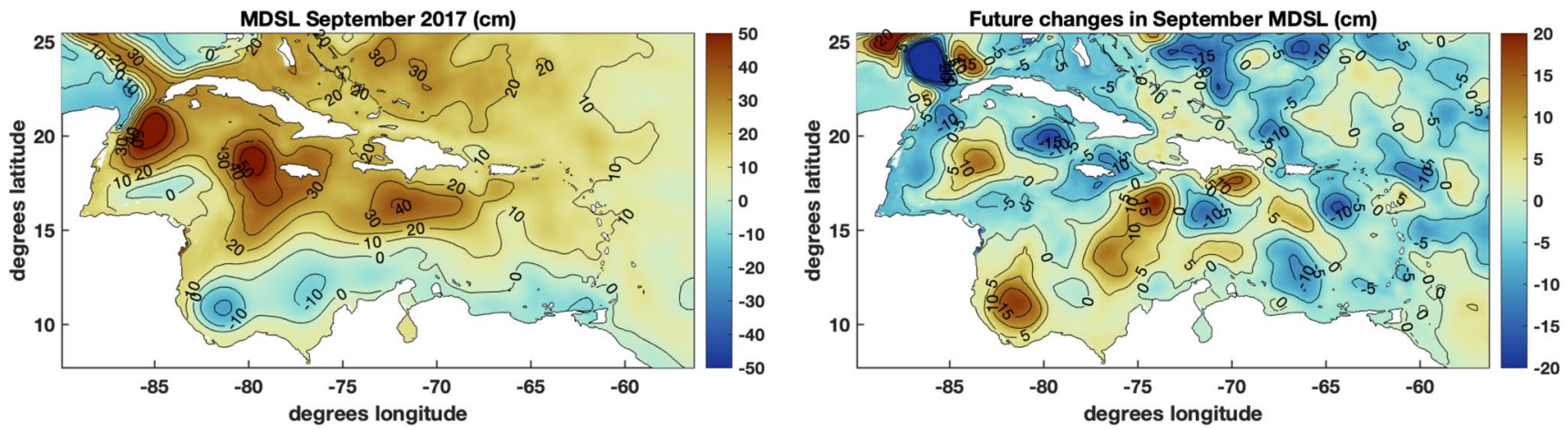

Figure A1. (a) Mean September 2017 dynamic sea level $(\mathrm{cm})$ and (b) the difference between 2100 and 2017. Note that the global mean sea-level of 2100 is offset by $76.63 \mathrm{~cm}$ from that of 2017 . 

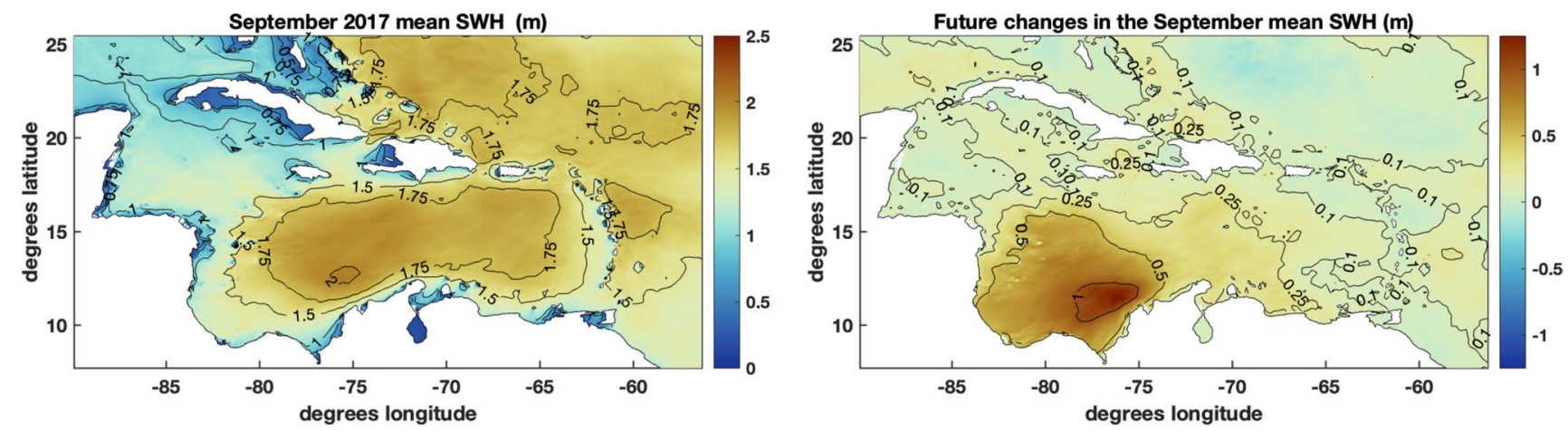

Figure A2. Mean significant wave height (m) for September 2017 (a) and (b) the difference between 2100 and 2017.

Figure A2a shows mean significant wave heights (SWH) for September 2017 with the difference between 2100 and 2017 results in Figure A2b. The mean SWH varies between $1 \mathrm{~m}$ in the west and $2 \mathrm{~m}$ in the east of the domain. The model projects an overall future increase of the September SWH in the Caribbean Sea. The largest increase of approximately $1.5 \mathrm{~m}$ occurs in the Colombia Basin. In the Venezuela Basin, the mean SWH is projected to increase by $40-50 \mathrm{~cm}$, while in Grenada Basin and Gulf of Honduras changes will not exceed $25 \mathrm{~cm}$. These changes in the mean SWH match in location with the projected increase in 10-m wind velocity magnitude (cf. Figure A3).

The mean tidal range (MTR) for September 2017 is shown in Figure A4a with again the difference between the 2100 and 2017 cases in Figure A4b. By 2100 the mean tidal range at the Nicaraguan shelf as well as at the southern coast of Cuba is found to decrease by more than $10 \mathrm{~cm}$. In several small areas south of Dominica positive or negative MTR variations of 5-7 cm are projected to occur, while changes do not exceed 2-3 cm elsewhere. Projected differences between the present and future mean tidal range for the stations around Puerto Rico and the Virgin Islands used in this study do not exceed $4 \mathrm{~cm}$ (cf. Table A1).

The predicted changes in the tidal range are caused by changes in the equilibrium tidal dynamics associated with the increased water depth as well as by the long-term tidal variability. Tidal dynamics in the Caribbean is affected by the 18.61-years lunar nodal cycle dominating in the eastern part of the sea and by the quasi 4.4-years cycle of perigean influence dominating in the west Caribbean (Haigh et al., 2011; Torres \& Tsimplis, 2011). Different phases of the cycles in 2017 and 2100 contribute to an increase (decrease) of the tidal range in the eastern (western) part of the Caribbean in 2100, all else being equal. The predicted reduction in M2 tidal amplitude at the Nicaraguan shelf (not shown) indicates that SLR pushes the system farther from the resonance.

In Table A1, also the 2DBC-model results regarding the impacts of the September 2017 hurricanes, as measured through the peak water levels (storm tide) and the peak storm surge, at the stations for both
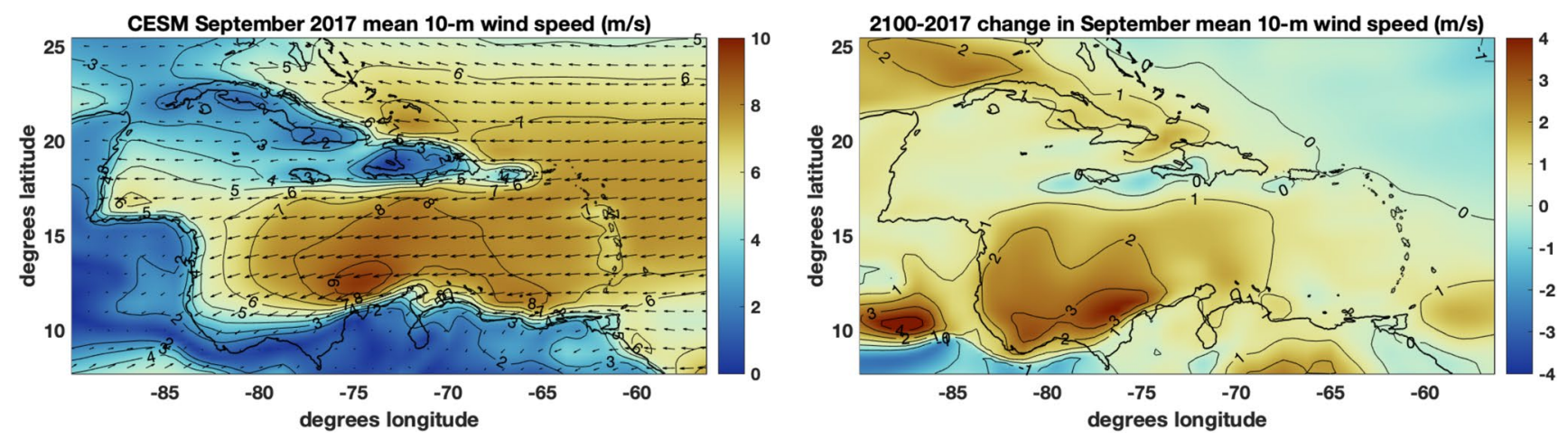

Figure A3. Mean 10-m wind speed and direction (m/s) for September 2017 (a) and (b) difference between 2100 and 2017. 

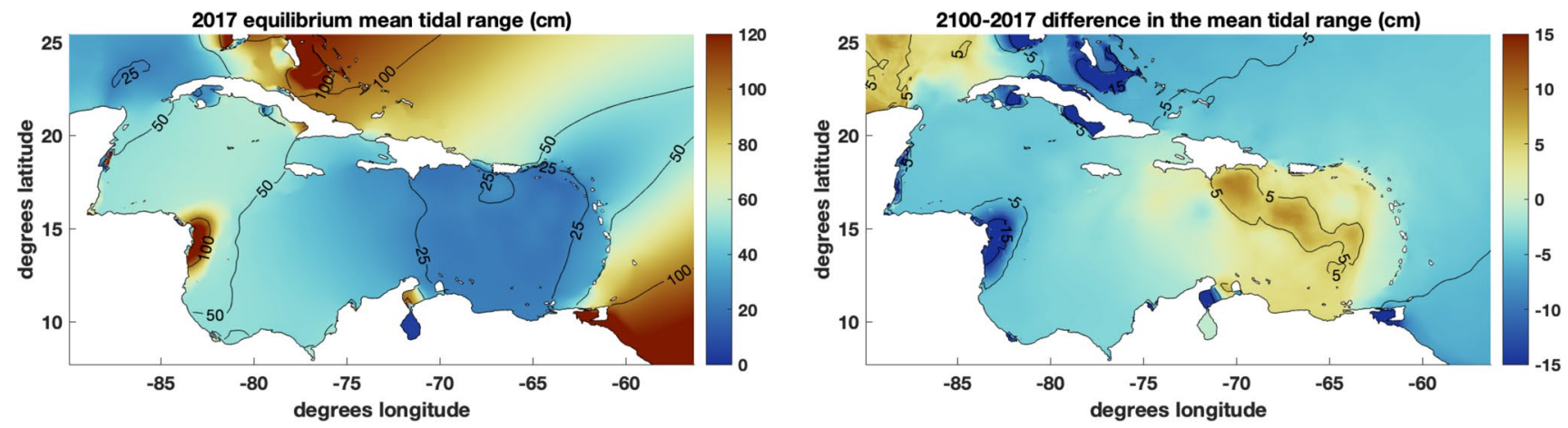

Figure A4. Mean tidal range (cm) for (a) September 2017 and (b) the difference between 2100 and 2017.

2017 and 2100 situations are listed. For all of the stations, the differences between the 2017 and 2100 storm-surge levels do not exceed 2-4 cm. Peak water levels (relative to the MSL at the station) are predicted to be up to $10 \mathrm{~cm}$ lower in the future with the exception of Irma-induced ones at stations 8 and 9. Higher peak water levels at these locations are associated with higher astronomical tides during the hurricane passage.

\section{Data Availability Statement}

All figures are prepared with Matlab R2019b. Part of the Matlab code as well as processed 2DBC model output is available in Kleptsova (2021), http://doi.org/10.5281/zenodo.4633983.

\section{Acknowledgments}

This work is part of the research program ALW-Caribbean with project 858.14.061 (SCENES), which is financed by the Netherlands Organisation for Scientific Research (NWO). The authors thank Michael Kliphuis (IMAU, UU) for his assistance with the CESM simulations. We would also like to show our gratitude to William Pringle and Brian Joyce (Computational Hydraulics Laboratory, University of Notre Dame) for their help with ADCIRC and setting up the numerical model. All computations were performed on the Cartesius at SURF-sara in Amsterdam. The tidal products were produced and distributed by Egbert \& Erofeeva, OSU, 2010 (https://www.tpxo.net/home). Ocean self-attraction and loading terms were produced by Noveltis, Legos, and CLS and distributed by AVISO+, with support from CNES (https://www.aviso. altimetry.fr/).

\section{References}

Alvera-Azca'rate, A., Barth, A., \& Weisberg, R. (2009). The surface circulation of the Caribbean sea and the Gulf of Mexico as inferred from satellite altimetry. Journal of Physical Oceanography, 39, 640-657. https://doi.org/10.1175/2008JPO3765.1

Andrade, C. A., \& Barton, E. D. (2000). Eddy development and motion in the Caribbean sea. Journal of Geophysical Research, 105(C11), 26191-26201. https://doi.org/10.1029/2000JC000300

Arns, A., Wahl, T., Dangendorf, S., \& Jensen, J. (2015). The impact of sea level rise on storm surge water levels in the northern part of the German Bight. Coastal Engineering, 96, 118-131. https://doi.org/10.1016/j.coastaleng.2014.12.002

Chelton, D. B., Schlax, M. G., Samelson, R. M., \& de Szoeke, R. A. (2007). Global observations of large oceanic eddies. Geophysical Research Letters, 34(15). L15606. https://doi.org/10.1029/2007GL030812

Church, J. A., Clark, P., Cazenave, A., Gregory, J., Jevrejeva, S., Levermann, A., \& Unnikrishnan, A. (2013). Sea level change. In T. F. Stocker, D. Qin, G.-K. Plattner, M. Tignor, S. Allen, J. Boschung, A. Nauels, Y. Xia, V. Bex, \& P. Midgley (Eds.), Climate change 2013: The physical science basis. Cambridge University Press.

Codiga, D. L., (2011). In Unified tidal analysis and prediction using the utide matlab functionsrep 01. Graduate School of Oceanography, University of Rhode Island. https://doi.org/10.13140/RG.2.1.3761.2008

Colbert, A. J., Soden, B. J., Vecchi, G. A., \& Kirtman, B. P. (2013). The impact of anthropogenic climate change on north Atlantic tropical cyclone tracks. Journal of Climate, 26(12), 4088-4095. https://doi.org/10.1175/JCLI-D-12-00342.1

Copernicus Climate Change Service (C3S). (2017). ERA5: Fifth generation of ECMWF atmospheric reanalyses of the global climate. Copernicus Climate Change Service Climate Data Store (CDS). https://cds.climate.copernicus.eu/cdsapp\#!/home

Delworth, T. L., \& Mann, M. E. (2000). Observed and simulated multidecadal variability in the northern hemisphere. Climate Dynamics, 16(9), 661-676. https://doi.org/10.1007/s003820000075

Dietrich, J., Zijlema, M., Westerink, J., Holthuijsen, L., Dawson, C., Luettich, R., et al. (2011). Modeling hurricane waves and storm surge using integrally-coupled, scalable computations. Coastal Engineering, 58(1), 45-65. https://doi.org/10.1016/j.coastaleng.2010.08.001

Dullaart, J. C. M., Muis, S., Bloemendaal, N., \& Aerts, J. C. J. H. (2020). Advancing global storm surge modelling using the new era5 climate reanalysis. Climate Dynamics, 54(1), 1007-1021. https://doi.org/10.1007/s00382-019-05044-0

Egbert, G. D., \& Erofeeva, S. Y. (2002). Efficient inverse modeling of barotropic ocean tides. Journal of Atmospheric and Oceanic Technology, 19(2), 183-204. https://doi.org/10.1175/1520-0426(2002)019<0183:EIMOBO>2.0.CO;2

Emanuel, K. (2005). Increasing destructiveness of tropical cyclones over the past 30 years. Nature, 436(7051), 686-688. https://doi. org/10.1038/nature03906

Evan, A. T. (2012). Atlantic hurricane activity following two major volcanic eruptions. Journal of Geophysical Research, 117(D6), D06101. https://doi.org/10.1029/2011JD016716

Evan, A. T., Foltz, G. R., Zhang, D., \& Vimont, D. J. (2011). Influence of african dust on ocean-atmosphere variability in the tropical atlantic. Nature Geoscience, 4(11), 762-765. https://doi.org/10.1038/ngeo1276

Evan, A. T., Vimont, D. J., Heidinger, A. K., Kossin, J. P., \& Bennartz, R. (2009). The role of aerosols in the evolution of tropical north atlantic ocean temperature anomalies. Science, 324(5928), 778-781. https://doi.org/10.1126/science.1167404

Garratt, J. R. (1977). Review of drag coefficients over oceans and continents. Monthly Weather Review, 105(7), 915-929. https://doi.org/10. 1175/1520-0493(1977)105<0915:RODCOO >2.0.CO;2 
Giri, C., Ochieng, E., Tieszen, L. L., Zhu, Z., Singh, A., Loveland, T., et al. (2011). Status and distribution of mangrove forests of the world using earth observation satellite data. Global Ecology and Biogeography, 20(1), 154-159. https://doi.org/10.1111/j.1466-8238.2010.00584.X

Gregory, J. M., Griffies, S. M., Hughes, C. W., Lowe, J. A., Church, J. A., Fukimori, I., et al. (2019). Concepts and terminology for sea level: Mean, variability and change, both local and global. Surveys in Geophysics, 40(6), 1251-1289. https://doi.org/10.1007/s10712-019-09525-Z

Haigh, I. D., Eliot, M., \& Pattiaratchi, C. (2011). Global influences of the 18.61 year nodal cycle and 8.85 year cycle of lunar perigee on high tidal levels. Journal of Geophysical Research: Oceans, 116(C6). C06025. https://doi.org/10.1029/2010JC006645

Haigh, I. D., Pickering, M. D., Green, J. A. M., Arbic, B. K., Arns, A., Dangendorf, S., et al. (2020). The tides they are a-changin': A comprehensive review of past and future nonastronomical changes in tides, their driving mechanisms, and future implications. Reviews of Geophysics, 58(1), e2018RG000636. https://doi.org/10.1029/2018RG000636

Hemer, M. A., Fan, Y., Mori, N., Semedo, A., \& Wang, X. L. (2013). Projected changes in wave climate from a multi-model ensemble. Nature Climate Change, 3(5), 471-476. https://doi.org/10.1038/nclimate1791

Hu, A., Meehl, G. A., Han, W., \& Yin, J. (2011). Effect of the potential melting of the greenland ice sheet on the meridional overturning circulation and global climate in the future. Deep Sea Research Part II: Topical Studies in Oceanography, 58(17), 1914-1926. https://doi. org/10.1016/j.dsr2.2010.10.069

Idier, D., Bertin, X., Thompson, P., \& Pickering, M. D. (2019). Interactions between mean sea level, tide, surge, waves and flooding: Mechanisms and contributions to sea level variations at the coast. Surveys in Geophysics, 40(6), 1603-1630. https://doi.org/10.1007/ s10712-019-09549-5

IPCC. (2019). In H. O. Pörtner, D. C. Roberts, V. Masson-Delmotte, P. Zhai, M. Tignor, E. Poloczanska, K. Mintenbeck, A. Alegría, M. Nicolai, A. Okem, J. Petzold, B. Rama, \& N. M. Weyer (Eds.), IPCC special report on the ocean and Cryosphere in a changing climate. In press.

James, R. K., Lynch, A., Herman, P. M. J., van Katwijk, M. M., van Tussenbroek, B. I., Dijkstra, H. A., et al. (2020). Tropical biogeomorphic seagrass landscapes for coastal protection: Persistence and wave attenuation during major storms events. Ecosystems, 24, 301-318. https://doi.org/10.1007/s10021-020-00519-2

James, R. K., Silva, R., van Tussenbroek, B. I., Escudero-Castillo, M., Mariño-Tapia, I., Dijkstra, H. A., et al. (2019). Maintaining tropical beaches with seagrass and algae: A promising alternative to engineering solutions. BioScience, 69(2), 136-142. https://doi.org/10.1093/ biosci/biy154

Joyce, B. R., Gonzalez-Lopez, J., Van der Westhuysen, A. J., Yang, D., Pringle, W. J., Westerink, J. J., \& Cox, A. T. (2019). U.S. IOOS coastal and ocean modeling testbed: Hurricane-induced winds, waves, and surge for deep ocean, reef-fringed islands in the Caribbean. Journal of Geophysical Research: Oceans, 124(4), 2876-2907. https://doi.org/10.1029/2018JC014687

Kendall, M., Kruer, C., Buja, K., Christensen, J., Finkbeiner, M., \& Monaco, M. (2001). Methods used to map the benthic habitats of Puerto Rico and the U. S. Virgin Islands. NOAA/NOS Biogeography Program Technical Re-port.

Kennedy, A. B., Westerink, J. J., Smith, J. M., Hope, M. E., Hartman, M., Taflanidis, A. A., et al. (2012). Tropical cyclone inundation potential on the Hawaiian Islands of Oahu and Kauai. Ocean Modelling, 52-53, 54-68. https://doi.org/10.1016/j.ocemod.2012.04.009

Kerr, P. C., Martyr, R. C., Donahue, A. S., Hope, M. E., Westerink, J. J., Luettich, R. A., Jr, et al. (2013). U.s. ioos coastal and ocean modeling testbed: Evaluation of tide, wave, and hurricane surge response sensitivities to mesh resolution and friction in the gulf of mexico. Journal of Geophysical Research: Oceans, 118(9), 4633-4661. https://doi.org/10.1002/jgrc.20305

Keyzer, L., Herman, P., Smits, B., Pietrzak, J., James, R., Candy, A., et al. (2020). The potential of coastal ecosystems to mitigate the impact of sea-level rise in shallow tropical bays. Estuarine, Coastal and Shelf Science, 246, 107050. https://doi.org/10.1016/j.ecss.2020.107050

Kjerfve, B. (1981). Tides of the caribbean sea. Journal of Geophysical Research, 86(C5), 4243-4247. https://doi.org/10.1029/JC086iC05p04243

Kleinosky, L. R., Yarnal, B., \& Fisher, A. (2007). Vulnerability of hampton roads, virginia to storm-surge flooding and sea-level rise. Natural Hazards, 40(1), 43-70. https://doi.org/10.1007/s11069-006-0004-z

Kleptsova, O. S. (2021, March). Okleptsova/tc-caribbean, Zenodo. https://doi.org/10.5281/zenodo.463398310.5281/zenodo.4633983

Klotzbach, P. J., \& Gray, W. M. (2008). Multidecadal variability in north atlantic tropical cyclone activity. Journal of Climate, 21(15), 3929-3935. https://doi.org/10.1175/2008JCLI2162.1

Knutson, T., Camargo, S. J., Chan, J. C. L., Emanuel, K., Ho, C.-H., Kossin, J., \& Wu, L. (2019). Tropical cyclones and climate change assessment: Part ii. projected response to anthropogenic warming. Bulletin of the American Meteorological Society, 101(3). https://doi. org/10.1175/BAMS-D-18-0194.1

Knutson, T. R., Sirutis, J. J., Vecchi, G. A., Garner, S., Zhao, M., Kim, H.-S., et al. (2013). Dynamical downscaling projections of twenty-first-century Atlantic hurricane activity: CMIP3 and CMIP5 model-based scenarios. Journal of Climate, 26(17), 6591-6617. https:// doi.org/10.1175/jcli-d-12-00539.1

Kodaira, T., Thompson, K. R., \& Bernier, N. B. (2016). The effect of density stratification on the prediction of global storm surges. Ocean Dynamics, 66(12), 1733-1743. https://doi.org/10.1007/s10236-016-1003-6

Kossin, J. P., Olander, T. L., \& Knapp, K. R. (2013). Trend analysis with a new global record of tropical cyclone intensity. Journal of Climate, 26(24), 9960-9976. https://doi.org/10.1175/JCLI-D-13-00262.1

Landsea, C. W., Vecchi, G. A., Bengtsson, L., \& Knutson, T. R. (2010). Impact of duration thresholds on atlantic tropical cyclone counts. Journal of Climate, 23(10), 2508-2519. https://doi.org/10.1175/2009JCLI3034.1

McDougall, T. J., \& Barker, P. M. (2011). Getting started with teos-10 and the gibbs seawater (gsw) oceanographic toolbox. 28 pp., scor/iapsowg127. (Tech. Rep.).

Melet, A., Meyssignac, B., Almar, R., \& Le Cozannet, G. (2018). Under-estimated wave contribution to coastal sea-level rise. Nature Climate Change, 8(3), 234-239. https://doi.org/10.1038/s41558-018-0088-y

Metzger, E. J., Helber, R. W., Hogan, P. J., Posey, P. G., Thoppil, P. G., Townsend, T. L., \& Phelps, M. W. (2017). Global ocean forecast system 3.1 validation test (Tech. Rep.) (pp. 39529-45004). Naval Research Laboratory, Stennis Space Center.

Mousavi, M. E., Irish, J. L., Frey, A. E., Olivera, F., \& Edge, B. L. (2011). Global warming and hurricanes: The potential impact of hurricane intensification and sea level rise on coastal flooding. Climatic Change, 104(3-4), 575-597. https://doi.org/10.1007/s10584-009-9790-0

Murakami, H., Li, T., \& Hsu, P.-C. (2014). Contributing factors to the recent high level of accumulated cyclone energy (ace) and power dissipation index (pdi) in the north atlantic. Journal of Climate, 27(8), 3023-3034. https://doi.org/10.1175/JCLI-D-13-00394.1

Mycoo, M. A. (2018). Beyond 1.5 C: Vulnerabilities and adaptation strategies for Caribbean Small Island Developing States. Regional Environmental Change, 18(8), 2341-2353. https://doi.org/10.1007/s10113-017-1248-8

Nurse, L., McLean, R., Agard, J., Briguglio, L., Duvat-Magnan, V., Pelesikoti, N., et al. (2014). Small islands. In Barros et al. (Eds.), Climate change 2014: Impacts, Adaptation, and vulnerability. Part B: Regional aspects. Contribution of working group II to the fifth assessment report of the intergovernmental panel on climate change (p. pp. 1613-1654). Cambridge University Press.

Padua, D., (Ed.), (2011). Community earth system model (cesm) (pp. 351). https://doi.org/10.1007/978-0-387-09766-4_2389 
Pickering, M., Horsburgh, K., Blundell, J., Hirschi, J.-M., Nicholls, R., Verlaan, M., \& Wells, N. (2017). The impact of future sea-level rise on the global tides. Continental Shelf Research, 142, 50-68. https://doi.org/10.1016/j.csr.2017.02.004

Pringle, W. J., Gonzalez-Lopez, J., Joyce, B. R., Westerink, J. J., \& van der Westhuysen, A. J. (2019). Baroclinic coupling improves depth-integrated modeling of coastal sea level variations around Puerto Rico and the U.S. Virgin Islands. Journal of Geophysical Research: Oceans, 124(3), 2196-2217. https://doi.org/10.1029/2018JC014682

Pringle, W. J., Wirasaet, D., Suhardjo, A., Meixner, J., Westerink, J. J., Kennedy, A. B., \& Nong, S. (2018). Finite-element barotropic model for the indian and western pacific oceans: Tidal model-data comparisons and sensitivities. Ocean Modelling, 129, 13-38. https://doi. org/10.1016/j.ocemod.2018.07.003

Pringle, W. J., Wirasaet, D., \& Westerink, J. J. (2018). Modifications to internal tide conversion parameterizations and implementation into barotropic ocean models. EarthArXiv. Retrieved from eartharxiv.org/84w53

Quarless, D. (2018). Irma and Maria by numbers. In FOCUS Magazine of the Caribbean development and Cooperation Committee (CDCC).

Resio, D., \& Westerink, J. (2008). Modeling the physics of storm surges. Physics Today, 61, 33-38. https://doi.org/10.1063/1.2982120

Shchepetkin, A. F., \& McWilliams, J. C. (2005). The regional oceanic modeling system (roms): A split-explicit, free-surface, topography-following-coordinate oceanic model. Ocean Modelling, 9(4), 347-404. https://doi.org/10.1016/j.ocemod.2004.08.002

Simpson, M., Scott, D., Harrison, M., Silver, N., O'Keeffe, E., Sim, R., \& McSharry, P. (2010). Quantification and magnitude of Losses and Damages resulting from the impacts of climate change: Modelling the transformational impacts and Costs of sea level rise in the caribbean (summary Document). : United Nations Development Programme (UNDP).

Smagorinsky, J. (1963). General circulation experiments with the primitive equations. Monthly Weather Review, 91(3), 99-164. https://doi. org/10.1175/1520-0493(1963)091<0099:GCEWTP>2.3.CO;2

Smith, J. M., Cialone, M. A., Wamsley, T. V., \& McAlpin, T. O. (2010). Potential impact of sea level rise on coastal surges in southeast louisiana. Ocean Engineering, 37(1), 37-47. https://doi.org/10.1016/j.oceaneng.2009.07.008

Stocker, T., Qin, D., Plattner, G.-K., Alexander, L., Allen, S., Bindoff, N., \& Xie, S.-P. (2013). Technical summary [Book Section], et al. (Eds.), In Climate change 2013: The physical science basis. contribution of working group $i$ to the fifth assessment report of the intergovernmental panel on climate change (pp. 1535-2116). Cambridge University Press. Retrieved from www.climatechange2013.org

Torres, R. R., \& Tsimplis, M. N. (2011). Tides and long-term modulations in the caribbean sea. Journal of Geophysical Research, 116(C10). C10022. https://doi.org/10.1029/2011JC006973

Torres, R. R., \& Tsimplis, M. N. (2013). Sea-level trends and interannual variability in the Caribbean Sea. Journal of Geophysical Research: Oceans, 118(6), 2934-2947. https://doi.org/10.1002/jgrc.20229

van Westen, R. M., Dijkstra, H. A., van der Boog, C. G., Katsman, C. A., James, R. K., Bouma, T. J., et al. (2020). Ocean model resolution dependence of Caribbean sea-level projections. Scientific Reports, 10(1), 14599. https://doi.org/10.1038/s41598-020-71563-0

Villarini, G., \& Vecchi, G. A. (2012). Twenty-first-century projections of North Atlantic tropical storms from CMIP5 models. Nature Climate Change, 2(8), 604-607. https://doi.org/10.1038/nclimate1530

Villarini, G., \& Vecchi, G. A. (2013). Projected increases in North Atlantic Tropical Cyclone Intensity from CMIP5 Models. Journal of Climate, 26(10), 3231-3240. https://doi.org/10.1175/JCLI-D-12-00441.1

Walsh, K. J., McBride, J. L., Klotzbach, P. J., Balachandran, S., Camargo, S. J., Holland, G., et al. (2016). Tropical cyclones and climate change. WIREs Climate Change, 7(1), 65-89. https://doi.org/10.1002/wcc.371

Webb, A., Shimura, T., \& Mori, N. (2018). A high-resolution future wave climate projection for the coastal northwestern Atlantic. Journal of Japan Society of Civil Engineers, Ser. B2 (Coastal Engineering), 74(2). https://doi.org/10.2208/kaigan.74.I134510.2208/kaigan.74.i_1345

Willmott, C. J. (1981). On the validation of models. Physical Geography, 2(2), 184-194. https://doi.org/10.1080/02723646.1981.10642213

Wolanski, E., Mazda, Y., \& Ridd, P. (1992). Mangrove hydrodynamics. In Tropical mangrove ecosystems (pp. 43-62). American Geophysical Union (AGU). https://doi.org/10.1029/CE041p0043

Wolf, J., \& Woolf, D. K. (2006). Waves and climate change in the northeast Atlantic. Geophysical Research Letters, 33(6). https://doi. org/10.1029/2005gl025113 